\title{
NUEVOS EQUINODERMOS (CISTIDEOS Y BLASTOZOOS) DEL ORDOVÍCICO DE LA CORDILLERA IBÉRICA (NE ESPAÑA)
}

\author{
Juan Carlos GUTIÉRREZ-MARCO', Jean CHAUVEL ${ }^{2}$ \\ y Bermudo MELÉNDEZ' \\ ' UEI y Departamento de Paleontología, Instituto de Geología Económica (CSIC-UCM), \\ Facultad de Ciencias Geológicas, 28040 Madrid. \\ ? Universidad de Rennes (Francia). Fallecido durante la fase inicial de preparación de este \\ trabajo.
}

Gutiérrez-Marco, J.C., Chauvel, J. y Meléndez, B. 1996. Nuevos equinodermos (cistideos y blastozoos) del Ordovícico de la Cordillera Ibérica (NE España). [New echinoderms (cystoids and blastozoans) from the Ordovician of the Iberian Cordillera (NE Spain)]. Revista Española de Paleontología, 11 (1), 100-119. ISSN 0213-6937.

\begin{abstract}
Primitive echinoderms from diverse Middle and Upper Ordovician localities in the Iberian Cordillera (NE Spain) are described and illustrated herein. Shales and sandstones of the La Venta and Castillejo Formations have yielded scarce diploporids (Calix and an unidentified aristocystitid). Younger calcareous shales and sandstones of the Fombuena Formation and "Bronchales Beds" include a diverse assemblage of Rhombifera (Caryocrinites, Heliocrinites, Rhombifera and undetermined hemicosmitids), Diploporita (Calix? and unidentified sphaeronitid); and the primitive blastoid Mespilocystites. The echinoderm and brachiopod assemblages of these units are in part conspecific with those of the Bohemian Vinice and Zahorany Formations and are significant in correlating Ordovician strata in the Mediterranean province.

The unusual rhombiferan Rhombifera bohemica is described for the first time from the Iberian Peninsula, and the holotypes of Heliocrinites? isabellae and H.? sampelayanus are redescribed and reillustrated. A new coronate species (Mespilocystites lemenni) is proposed.
\end{abstract}

Keywords: Echinodermata, Diploporita, Rhombifera, Blastoidea, Coronata, new species, Ordovician, Iberian Cordillera, Spain.

\section{RESUMEN}

Se describen los equinodermos ordovícicos obtenidos en diversas unidades pre-ashgillienses de ambas Ramas de la Cordillera Ibérica. Las pizarras y areniscas del Dobrotiviense (Fms. La Venta y Castillejo) han proporcionado Calix y aristocystítidos indeterminados, mientras que las areniscas y margas con briozoos del VinicienseZahoraniense (Fm. Fombuena y "Capas de Bronchales") reúnen una asociación más variada de diploporitos (Calix?, Sphaeronitida indet.), rombíferos (Caryocrinites, Heliocrinites, Rhombifera, Hemicosmitida indet.) y primitivos blastoideos (Mespilocystites). El conjunto de equinodermos y braquiópodos registrados presenta afinidades a nivel específico con Bohemia, lo cual reviste un gran interés para la correlación dentro del Ordovícico mediterráneo.

Se da la primera descripción para la Península del cistideo Rhombifera bohemica y la revisión de las especies Heliocrinites? isabellae y H.? sampelayanus, que se propone restringir a sus holotipos respectivos. La nueva especie Mespilocystites lemenni contribuye al conocimiento de los controvertidos Coronata en el Ordovícico perigondwánico, y se analizan otros hallazgos de la subclase en la Península Ibérica.

Palabras clave: Equinodermos, Diploporita, Rhombifera, Blastoidea, Coronata, nueva especie, Ordovícico, Cordillera Ibérica, España.

\section{INTRODUCCIÓN}

Las asociaciones de pelmatozoos del Ordovícico de la Cordillera Ibérica han sido objeto de diversos estudios tras su descubrimiento, a finales del siglo pasado
(Dereims, 1898), en las unidades calcáreas que configuran el techo de la sucesión de este Período en las Cadenas Ibéricas Orientales (Rama Aragonesa).

Los trabajos de Lotze (1929), Meléndez (1944,1959), Meléndez y Hevia (1947), Wolf (1976), Chauvel et al. 
(1975) y Chauvel y Le Menn (1979), especialmente los dos últimos, han puesto de manifiesto la existencia de 17 formas diferentes de cistideos, 6 morfotipos de placas columnares de crinoides, un blastozoo y un asterozoo indeterminado, en distintos afloramientos de la Formación Calizas de Cistideos de la región de Fombuena-Luesma (provincia de Zaragoza: cf. Villas, 1983 y Hammann, 1992, para la definición y sinónimos de esta unidad litoestratigráfica). No obstante, la presencia de equinodermos en depósitos anteriores a las calizas del Ashgill es menos frecuente, y cuenta con pocos antecedentes en la literatura geológica regional. Por todo ello, los objetivos del presente trabajo son, por un lado, recopilar los datos existentes sobre equinodermos anteriores al Ashgill (fundamentalmente Dobrotiviense-Zahoraniense) en la Cordillera Ibérica; y por otro, describir detalladamente aquellos ejemplares o taxones que revistan un interés paleontológico especial.

Este artículo constituye la versión actualizada del texto de una comunicación presentada en las VII Jornadas de Paleontología (Gutiérrez Marco et al., 1991). La identificación y descripciones morfológicas de la mayoría de los diploporitos y rombíferos que figuran en el apartado sistemático (a excepción de los géneros Heliocrinites y Rhombifera) son obra de J. Chauvel y B. Meléndez; el resto del trabajo es responsabilidad del primer firmante. El material descrito e ilustrado se encuentra depositado en el Museo Geominero (ITGE, Madrid).

La terminología cronoestratigráfica empleada se fundamenta en la escala regional mediterránea de Havlícek y Marek (1973), indicándose, en lo posible, su correlación tentativa con la escala local británica revisada por Fortey et al. (1995). El piso Dobrotiviense resultaría en parte equivalente al Llandeiliense (Llanvirn superior) y al Aureluciense basal (Caradoc temprano), en opinión de Gutiérrez Marco et al. (1995), trabajo en el que se justifica detalladamente la aplicabilidad de la escala mediterránea en el SO de Europa.

\section{ANTECEDENTES}

La primera mención sobre el hallazgo de equinodermos pre-ashgillienses en la región estudiada se debe a Meléndez (1944), quien describe los cistideos y crinoides encontrados en las proximidades de Fombuena (Zaragoza), en unos niveles de pizarras descalcificadas del Ordovícico Superior, que equivalen aquí al yacimiento FB-IIIB del apartado siguiente (parte inferior de la Formación Fombuena). Posteriormente, Carls (1975) refiere también la presencia de grandes cistideos en la misma zona, que sin embargo proceden de niveles algo más antiguos (Ordovícico Medio: parte alta de la Formación Castillejo) y fueron determinados por Kolb (1978) como Calix sp. El material original del primero de los trabajos considerados hasta ahora ha podido revisarse parcialmente con ocasión de este estudio (ver apartado sistemático), mientras que los cistideos del Dobrotiviense originales de los últimos trabajos se encuentran depositados en el Instituto de Paleontología de la Universidad de
Würzburg (Alemania). La consulta de los mismos verificada por uno de los autores (J.C.G-M.), ha puesto de manifiesto la existencia de dos ejemplares de gran tamaño, casi completos, que hemos identificado como Calix rouaulti Chauvel forma $f$ (sensu Chauvel, 1980).

En lo que respecta a la Rama Castellana del Sistema Ibérico, los primeros hallazgos de equinodermos ordovícicos previos al Ashgill se deben a Riba (1959), quien refiere la presencia de Echinosphaerites murchisoni Vern. y Barr., junto con placas columnares de crinoides, en la parte alta de la unidad equivalente a la Formación La Venta, en el Macizo de Sierra Carbonera, situado al sur de Gea de Albarracín (Teruel). Esta localidad fue revisada posteriormente por Gutiérrez-Marco (1981, 1986), encontrándose en ella fragmentos aborales y concentraciones de placas desarticuladas (con y sin tubérculos) referibles con certeza al género Calix, probablemente a $C$. rouaulti Chauvel (="Echinosphaerites murchisoni": Chauvel y Meléndez in GutiérrezMarco et al., 1984a), acompañados por diversos trilobites y braquiópodos del Dobrotiviense. Los trabajos de Gutiérrez-Marco $(1981,1986)$ refieren a su vez otra localidad contigua a la anterior que contiene Calix sp. (placas aisladas), correspondiendo a los niveles basales de areniscas de la Formación "Cuarcitas de la Serretilla", que representan horizontes algo más modernos dentro del Dobrotiviense. Finalmente, una tercera localidad fosilífera, descrita en los mismos trabajos, ha proporcionado en fecha reciente diversos braquiópodos, trilobites y equinodermos del Ordovícico Superior, parte de los cuales se describen en este estudio (punto CP-II), que se sitúan en los niveles arenosos de las "Capas de Bronchales" del Macizo del Collado de la Plata, al suroeste de Bezas (Teruel).

Fuera del propósito de este artículo queda la revisión de otros grupos como los crinoides, así como los equinodermos problemáticos descritos en la Sierra de la Demanda como Oryctoconus lobatus Colchen y Ubaghs, 1969, y que eran conocidos previamente en la Rama Aragonesa de la Cordillera Ibérica como Calix? dorecki Sdzuy (Scheuplein, 1970; Josopait, 1972; Wolf, 1976). Estos fósiles se concentran en horizontes conglomeráticos inmediatos al techo de la Formación Valconchán, constituyendo un buen nivel paleontológico de referencia, utilizado inicialmente para establecer la posición aproximada de la base local del Ordovícico (Wolf, 1980).

\section{SITUACIÓN DE LOS YACIMIENTOS}

En este trabajo se han investigado los cistideos encontrados en seis puntos situados en ambas Ramas de la Cordillera Ibérica, si bien el material paleontológico procede en su mayor parte de las Cadenas Ibéricas Orientales (Rama Aragonesa).

El yacimiento más antiguo desde el punto de vista estratigráfico se ubica en el término de Fombuena (Zaragoza), en un campo arado contiguo a un pequeño arroyo situado en la margen izquierda del Barranco de la Peña, aproximadamente $400 \mathrm{~m}$ al SSO de la Piedra del Tormo (Fig. 
1d). Esta localidad (sigla de los ejemplares: FB-V) ha proporcionado exclusivamente restos del cistideo Calix rouaulti Chauvel (Lám. I, fig. 2), conservado en pizarras arenosas pertenecientes al tramo basal del Miembro Sierra de la Formación Castillejo (nomenclatura litoestratigráfica según Villas, 1983). De acuerdo con los horizontes paleontológicos reconocidos en secciones inmediatamente próximas a la localidad mencionada (Gutiérrez-Marco, 1980; Villas, 1985), tales niveles tendrían una edad Dobrotiviense, pudiendo ordenarse eventualmente dentro de la Biozona de Extensión de Heterorthina kerfornei (Villas, 1985).

Las localidades siguientes se corresponden con un mismo horizonte estratigráfico, perteneciente a las "margas de briozoos" del Miembro Piedra del Tormo de la Formación Fombuena, y están situadas próximas al punto anterior. En este caso, ambos yacimientos se localizan en los

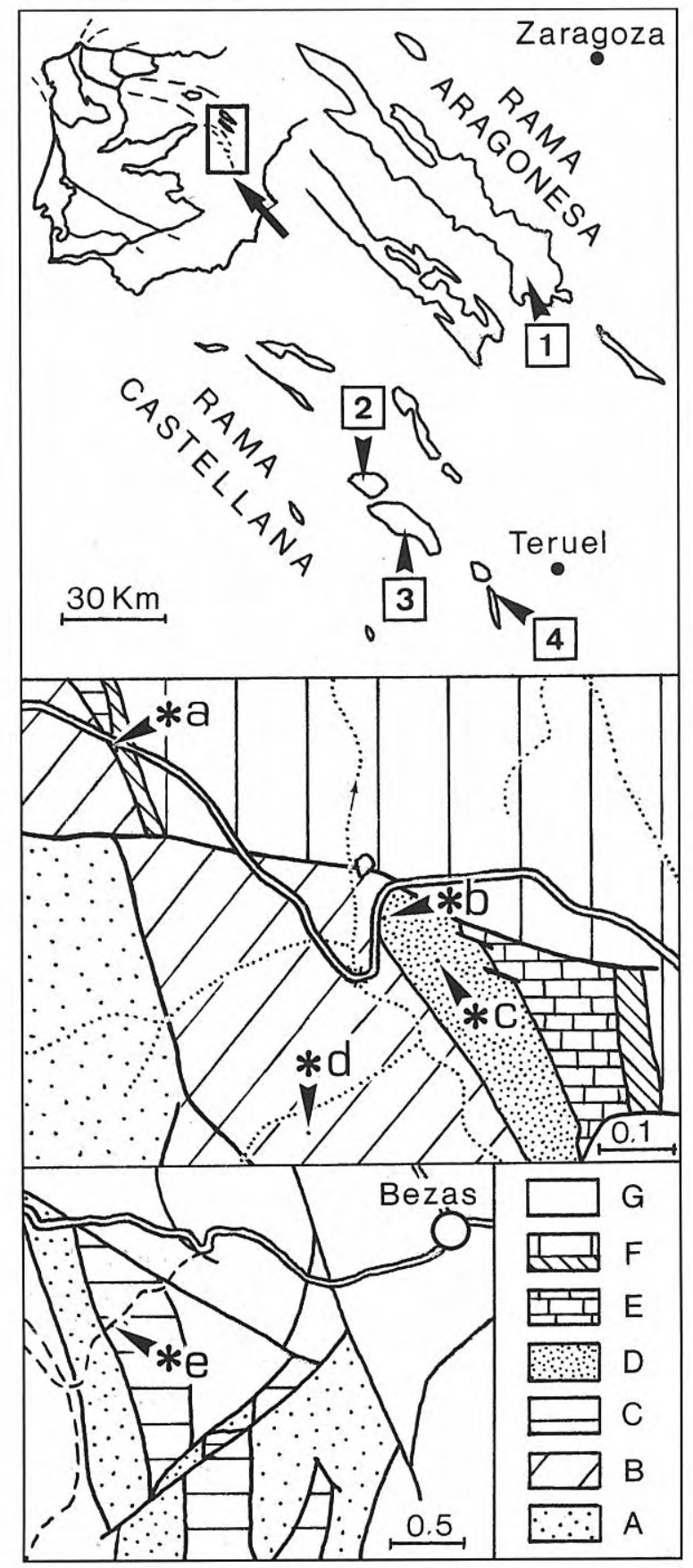

taludes de la carretera Badules-Herrera de los Navarros al oeste de Fombuena, a la altura en que ésta recorre ambas márgenes del Barranco de la Peña. El primer punto (FBIIIA) se sitúa en el km 20,150 (talud meridional), $400 \mathrm{~m}$ al NO de la Piedra del Tormo (Fig. 1a); mientras que el segundo (FB-IIIB, talud oriental), se localiza tan solo $100 \mathrm{~m}$ al SE de la Piedra del Tormo (Fig. 1b), correspondiendo al "yacimiento de Fombuena" estudiado por Meléndez (1944), y cuyos fósiles fueron atribuidos entonces al tránsito Silúrico/Devónico.

El estudio paleontológico de las localidades FB-IIIA/B ha permitido identificar la presencia en estos materiales de diversos briozoos, graptolitos bentónicos, braquiópodos (articulados e inarticulados), trilobites, moluscos (bivalvos, gasterópodos), equinodermos (cistideos, crinoides y blastozoos), posibles tabulados y raros cornulítidos y conodontos, que suman en total más de una veintena de especies, muchas de ellas aún por determinar. El conjunto de fósiles obtenido en ambos yacimientos es prácticamente el mismo, habida cuenta de su correspondencia estratigráfica y proximidad geográfica (distan menos de $500 \mathrm{~m}$ entre sí). De acuerdo con nuestras propias observaciones y trabajos anteriores (Meléndez, 1944; Carls, 1975; Gutiérrez-Marco, 1980, 1986; Villas, 1983, 1985, 1992), la relación de fósiles identificados hasta ahora en el tramo lumaquélico de pizarras margosas y en el nivel oolítico ferruginoso infrayacente, consta de Phylloporina lluecai (Meléndez, 1944), Batostoma? camarensis (Meléndez, 1944), Disteichia reticulata Sharpe, 1853, Jezercia chrustenicensis (Havlícek, 1950), Svobodaina armoricana Babin y Mélou, 1972, Gelidorthis meloui Villas, 1985, Rafinesquina cf. pseudoloricata Barrande, 1848, Rostricellula ambigena (Barrande, 1847), Aegiromena aquila intermedia Villas, 1992, Rostricellula marciali Villas, 1992, Saukrodictya tormoensis Villas, 1992, Triplesia cf. iberica Villas, 1985, Dravobia sp.1 Villas, 1992, Prionocheilus sp., Zetillaenus? sp., Reticulograptus erdtmanni Gutiérrez-Marco (nomen

Figura 1. Situación de los yacimientos estudiados con equinodermos ordovícicos. Recuadro superior: Esquema con las subdivisiones del Macizo Hespérico y localización de los núcleos paleozoicos de la Cordillera Ibérica. A la derecha, detalle de los mismos en las Ramas Aragonesa y Castellana. 1, yacimientos del área de Fombuena (Cadenas Ibéricas orientales); 2, yacimientos de Checa (Macizo del Nevera); 3, yacimiento de Noguera (Macizo del Tremedal); 4, yacimiento de Bezas (Macizo Collado de la Plata). Recuadro intermedio: Esquema geológico de un sector del Barranco de la Peña al O de Fombuena, indicando los puntos fosilíferos. a, FB-IIIA; b, FB-IIIB; c, FB-IV; d, FBV. Recuadro inferior: Esquema geológico del entorno del yacimiento CP-II (punto e del mapa), en el Collado de la Plata. Leyenda litológica: A, Cuarcita Armoricana (Ordovícico inferior); B, Formación Castillejo (OretanienseDobrotiviense); C, materiales del Ordovícico medio y superior indiferenciados cartográficamente; D, Formación Fombuena (Beroun); E, Formaciones Calizas de Cistideos y Pizarras de Orea (Kralodvoriense-Kosoviense); F, Formaciones Cuarcita de los Puertos y Bádenas (Silúrico); G, Materiales postpaleozoicos. Escala gráfica en km. 
nudum, 1986), Dictyonema (Dictyonema) isabellae Gutiérrez-Marco (nomen nudum, 1986), Acanthograptus pelaezi Gutiérrez-Marco (nomen nudum, 1986), Dendrograptus sp., Aspidograptus sp., Mespilocystites lemenni n. sp., Calix? cf. gutierrezi Chauvel y Meléndez, 1986, Sphaeronitida inc. fam., Caryocrinites cf. rugatus (Forbes, 1848), Hemicosmitida inc. fam., Heliocrinites? sampelayanus (Meléndez, 1944), Heliocrinites? isabellae (Meléndez, 1944), Heliocrinites sp. y Rhombifera bohemica Barrande, 1867.

Respecto a la datación del conjunto de estas "margas de briozoos" (7-7,5 $\mathrm{m}$ de potencia total), la asociación de braquiópodos presentes caracteriza la Sub-biozona de Coexistencia de $S$. armoricana y $G$. meloui (Biozona de Extensión de $S$. armoricana), equivalente al Viniciense (Serie Beroun) o al subpiso Soudleyense (Aureluciense: Caradoc temprano) dependiendo de la escala utilizada (Villas, 1985, 1992).

La asociación de equinodermos más moderna estudiada en este trabajo, previa a las Calizas de Cistideos, se sitúa igualmente al $\mathrm{O}$ de Fombuena, en la misma sección del Barranco de la Peña, en un punto próximo a los anteriores (Fig. 1c: loc. FB-VI). El yacimiento corresponde en este caso a intercalaciones de arenisca con cemento calcáreo y carácter lumaquélico, que se ubican en la alternancia de areniscas y pizarras del Miembro Huerva de la Formación Fombuena (Villas, 1983), aproximadamente $20 \mathrm{~m}$ por encima del techo de las "margas de briozoos" del Miembro Piedra del Tormo infrayacente (localidad Fombuena 4, horizonte 4b de Villas, 1985). Los niveles lumaquélicos contienen abundantes briozoos y braquiópodos, junto a un número mucho más reducido de restos de equinodermos (cistideos, blastozoos y crinoides), moluscos y trilobites. La relación de formas identificadas hasta ahora (Hammann et al., 1982; Villas, 1985, 1992 y observaciones propias) es la siguiente: Gelidorthis carlsi Villas, 1992, Dalmanella unguis unguis (Sowerby in Murchison, 1839), Svobodaina armoricana Babin y Mélou, 1972, Triplesia iberica Villas, 1985, Drabovia sp. 1 Villas, 1992, Rafinesquina lignani Villas, 1985, Rostricellula sp., Aegiria sp., Zetillaenus sp., Cekovia sp., Dalmanitina (D.) cf. acuta Hammann, 1971, Eccoptochile sp., Rhombifera sp., Diploporita indet. y Mespilocystites lemenni $\mathrm{n}$. sp.

La asociación de braquiópodos define la Sub-biozona de Coexistencia de $S$. armoricana y $R$. lignani, indicativa de la parte superior de la Biozona de Extensión de $S$. armoricana (Villas, 1985), que su autor correlaciona con el piso Zahoraniense de Bohemia (Cheneyense del Caradoc británico).

Por lo que se refiere al Paleozoico de la Rama Castellana de la Cordillera Ibérica, el yacimiento más productivo con equinodermos ordovícicos se ubica en el Macizo del Collado de la Plata, aproximadamente $2 \mathrm{~km}$ al SO de Bezas (Teruel), y corresponde a un tramo de areniscas ferruginosas pertenecientes a las denominadas "Capas de Bronchales" ó "Alternancia del Caradoc" (Aznar et al., 1983). El punto fosilífero se encuentra en el talud noroccidental de un camino que parte en dirección SO desde el km 23,2 de la carretera Bezas-Valdecuenca, cerca del contacto tectónico de las "Capas de Bronchales" con la
"Cuarcita Armoricana" (Fig. 1, localidad CP-II). La relación de especies identificadas en el yacimiento es prácticamente idéntica a la de los puntos FB-IIIA/B, por lo que el tramo estudiado puede correlacionarse con los niveles correspondientes de la Formación Fombuena en la Rama Aragonesa. El estudio preliminar emprendido en este trabajo ha permitido reconocer la presencia de Svobodaina armoricana Babin y Mélou, 1972, Zetillaenus ibericus Hammann, 1976, Prionocheilus sp., Reticulograptus erdtmanni Gutiérrez-Marco (nomen nudum, 1986), Mespilocystites lemenni n. sp. (localidad tipo), Calix? sp. cf. C. gutierrezi Chauvel y Meléndez, 1986, Hemicosmitida inc. fam., Rhombifera? sp., Crinoida indet. y Bryozoa indet. (Cryptostomata y Cheilostomata).

Respecto a la edad de la asociación, la presencia de $S$. armoricana es un firme indicador de la biozona homónima (Villas, 1985; Villas et al., 1995), que se correlaciona con los pisos Viniciense-Zahoraniense de la Serie Beroun mediterránea (Burrelliense-Cheneyense del Caradoc británico).

Otros dos yacimientos inéditos hasta ahora, con restos de equinodermos del Ordovícico superior, se sitúan en los Macizos del Tremedal y Nevera, pertenecientes tambien al basamento del gran anticlinorio mesozoico de la Sierra de Albarracín. En el Macizo del Tremedal, el techo de las "Capas de Bronchales" está indicado por un horizonte margoso descalcificado con restos de briozoos, que ha proporcionado una placa aislada de rombífero (Fig. 3b), muy semejante a las de las formas aquí descritas como Hemicosmitida inc. fam. En este caso sin embargo, su asociación con Ovalocephalus sp. hace suponer que el horizonte estratigráfico sea sensiblemente más moderno que el del miembro inferior de la Fm. Fombuena, de donde procede el material comparable. En este sentido, la distribución ibérica del citado trilobites hammatocnémido estaba restringida hasta ahora a las facies margosas de la Fm. Caliza de Cistideos, representativas de medios relativamente profundos, en dos localidades de la Rama Aragonesa de la Cordillera Ibérica (Hammann, 1992). El nuevo yacimiento estudiado se sitúa $1800 \mathrm{~m}$ al ONO de Noguera (Teruel), en el talud septentrional de la carretera TE-903 entre esta población y Orihuela del Tremedal (Km 26,8 aprox.).

El último punto investigado en el Macizo del Nevera, corresponde a los niveles de margas verdosas, con restos de briozoos y braquiópodos, infrayacentes a las Calizas de Cistideos, tratándose de la misma localidad descrita por Hafenrichter (1979, perfil IX, fig. 18 y lám. 3, fig. 2), donde la autora cita la presencia de restos indeterminables de cistideos. El yacimiento se sitúa $2750 \mathrm{~m}$ al E de Checa (Guadalajara), al N de la carretera que va desde esta localidad a Orea (Teruel). De aquí procede el resto desarticulado de una teca de un rombífero indeterminado, cuyas placas poseen umbos y pliegues radiales acusados, entre los que se marcan líneas de crecimiento comarginales (Fig. 3c). Su aspecto resulta muy similar al de muchos caryocystítidos, con los que provisionalmente asignamos nuestro material en nomenclatura abierta. Los braquiópodos encontrados en el mismo horizonte pertenecen a la "fauna de Nicolella" de edad Kralodvoriense, por lo que el punto representa el yacimiento más moderno de los estudiados, tal vez comparable a la 
localidad con equinosfaerítidos que cita Sacher (1963: fide Hafenrichter, 1979) en el cercano Macizo de Aragoncillo.

Desde el punto de vista paleobiogeográfico, las asociaciones de equinodermos del Dobrotiviense y Viniciense-Zahoraniense de la Cordillera Ibérica revisten un carácter típicamente mediterráneo, con géneros como Calix, Heliocrinites, Rhombifera o Mespilocystites, no registrados en estas edades fuera del ámbito del SO de Europa, Europa centro-meridional y $\mathrm{N}$ de Africa. Adicionalmente, el hallazgo de Rhombifera bohemica Barrande, una forma de Heliocrinites afín a $H$. helmhackeri (Barrande), y una especie nueva de Mespilocystites próxima a $M$. bohemicus Barrande, en las llamadas "margas de briozoos" de la Formación Fombuena, confirma entre los equinodermos las afinidades bohémicas a nivel de especie observadas por Villas $(1985,1992)$ en estos mismos niveles del Miembro Piedra del Tormo. Ello tiene un gran interés para la correlación bioestratigráfica y biocronológica iberobohémica en el seno del Ordovícico mediterráneo.

\section{DESCRIPCIONES SISTEMÁTICAS}

\author{
CLASE DIPLOPORITA Müller, 1854 \\ Superfamilia SPHAERONITIDA Neumayr, 1889 \\ Familia Aristocystitidae Neumayr, 1889 \\ Género Calix Rouault, 1851
}

Especie tipo: Calix sedgwickii Rouault, 1851.

\section{Calix rouaulti Chauvel, 1936 \\ Lám. I, fig. 2}

\section{Material estudiado}

Un ejemplar, FB-V 40, procedente de los primeros niveles de alternancias arenosas de la base del Miembro Sierra de la Formación Castillejo, Dobrotiviense.

\section{Observaciones}

El único ejemplar estudiado es un fragmento aboral perteneciente al molde externo de una teca alargada, en el que se distingue un tubérculo basal no recurvado, tres ciclos regulares de tubérculos espaciados entre sí, y el tránsito a una región oral carente de estas últimas estructuras.

Pese a que no se poseen otros detalles como la constitución de las fosetas diplopóricas, la morfología de la teca concuerda exactamente con la de $C$. rouaulti Chauvel forma typica (morfotipo $a$ ), una especie bien conocida en el Dobrotiviense de la Península Ibérica (Gutiérrez-Marco et al., 1984a), N de Africa (Chauvel, 1966) y Macizo Armoricano francés (Chauvel, 1980).

Calix? cf. gutierrezi Chauvel y Meléndez, 1986 (Lám. II, fig. 12-13, 18-19)

\section{Material estudiado}

2 ejemplares, CP-II 546a-b y FB-IIIB 1255, procedentes respectivamente de las "Capas de Bronchales" y el Miembro
Piedra del Tormo de la Formación Fombuena; VinicienseZahoraniense.

\section{Descripción}

CP-II 546a-b es el molde interno + externo de una teca incompleta y deformada. En su superficie interna se distinguen placas de contorno poligonal, algunas de las cuales poseen un tubérculo mamelonar, con fosetas diplopóricas profundas y poligonales (Lám.II, fig.19). En el molde interno correspondiente se aprecian fosetas internas alargadas y en disposición irregular, aunque en ocasiones se alinean en el borde de las suturas entre dos placas (Lám.II, fig.18).

El ejemplar FB-IIIB 1255 consiste en el molde externo de algunas placas aplanadas a ligeramente convexas, ornadas por una red de fosetas poligonales en cuyo interior se aprecian muy bien las aperturas irregulares de los diploporos (Lám.II, fig.13).

\section{Observaciones}

La presencia de fosetas poligonales ha sido señalada en diversos diploporitos de teca globulosa como Tholocystis o Sphaeronites, aunque combinadas con tubérculos picudos sólo se conocen en Calix gutierrezi Chauvel y Meléndez, 1986. Ésta constituye una de las especies más modernas del género, descrita originalmente en las lumaquelas terminales de los "Bancos Mixtos" de Sierra Morena, recientemente atribuidas al Bohdaleciense o Ashgill inferior (Pusgilliense: Gutiérrez-Marco y Rábano, 1987). La especie se conoce a través de pocos ejemplares, a veces de grandes dimensiones, cuyas placas principales e intercalares poseen siempre tubérculos de distintas morfologías. La comparación con $C$. gutierrezi del ejemplar FB-IIIB 1255 se basa únicamente en las fosetas poligonales y las grandes dimensiones que alcanzaría la teca. No obstante, en nuestras últimas colectas de equinodermos en la Caliza de Cistideos de Fombuena (Rebollarejo) hemos encontrado un diploporito, no descrito previamente (Sphaeronites?), con fosetas diplopóricas poligonales y carente de tubérculos, cuya teca supera $6 \mathrm{~cm}$ de diámetro y por tanto puede estar también relacionado con este último material considerado aquí en nomenclatura abierta.

\section{Aristocystitidae gen. et sp. indet. Lám. I, fig. 1}

\section{Material estudiado}

Diversos moldes de placas aisladas contenidos en las muestras FB-V 41 a 43, procedentes de la base del Miembro Sierra de la Formación Castillejo; Dobrotiviense.

\section{Descripción}

Las distintas placas examinadas muestran algunas variaciones en su espesor y características. Junto a placas delgadas (espesor entre 0,75 y $1 \mathrm{~mm}$ ), atravesadas por canales cilíndricos de hasta $0,4 \mathrm{~mm}$ de diámetro, existen otras muy espesas y cuboides (altura 2,5-4 mm). Éstas muestran canales semejantes a los anteriores, pero netamente agrupados por pares que se abren en la cara 
interna de las placas. La cara externa de una placa en la muestra FB-V 42 es lisa, denotando la presencia de un epiestereoma denso. En las caras laterales de las placas, donde éstas se articulan entre sí, se distinguen también numerosos canales correspondientes a poros adheridos que rara vez se ramifican y a menudo parecen atravesar la pared abriéndose en la cara lateral. La concentración de éstos es tal que en algunas placas gruesas los poros periféricos parecen anastomosarse. Por el contrario, en otras placas más delgadas y parcialmente articuladas de la muestra FB-V 41, se observan escasos poros que atraviesan lateralmente las placas, y entre ellos unas arrugas apretadas paralelas al borde interno de éstas.

\section{Observaciones}

Los caracteres internos tan particulares de las placas y los poros que las atraviesan, concuerdan con los descritos en algunos aristocystítidos como Aristocystites (Parsley, 1990) o Pachycalix (Chauvel, 1941). Sin embargo, para precisar su determinación es necesario disponer de buen material en mejor estado de conservación, por lo que la cuestión queda condicionada a futuros hallazgos.

Sphaeronitida inc. fam.

Fig. 2a-c; Lám. II, fig. 7-8, 16-17

\section{Material estudiado}

5 muestras (FB-IIIB 1256 a 1260) conteniendo diversos fragmentos tecales con placas en conexión (dos con molde externo), procedentes de las "margas de briozoos" del Miembro Piedra del Tormo de la Formación Fombuena, Viniciense.

\section{Descripción}

El fragmento de la teca mejor conservado (FB-IIIB 1256 a-b) mide una docena de $\mathrm{cm}^{2}$ y es ligeramente arqueado en sección transversal. Su superficie reúne una cuarentena de placas cuya forma, tamaño y disposición es muy variable. Así, el número de lados oscila entre 3 y 9; las suturas entre las placas suelen ser rectilíneas, pero a menudo también curvilíneas e incluso francamente sinuosas. La disposición de las placas puede parecer irregular a primera vista, pero se reconocen algunos alineamientos superpuestos de placas medianas (por ejemplo $3 \times 4,5,4 \times 4,5 \mathrm{~mm}, \ldots .$. ). El eje mayor de otras placas más grandes $(7 \times 5 \mathrm{~mm})$ se dispone paralelo a los alineamientos anteriores, dando idea de la orientación perpendicular del eje de la teca. Las placas más pequeñas miden alrededor de $2 \times 2 \mathrm{~mm}$. En el molde interno se aprecian también estrías muy finas de crecimiento paralelas a las suturas de algunas placas.

La superficie externa de la teca muestra que el centro de las placas está sobreelevado y posee un aspecto mamelonar, que sólo se indica ligeramente en las placas más pequeñas. Los "tubérculos" correspondientes son cónicos, bastante regulares, y de base circular o elíptica, llegando a alcanzar hasta 1,25 mm de altura. En otros casos son dobles o toman el aspecto de crestas irregulares (con diversas cúspides) en las placas de mayor tamaño.

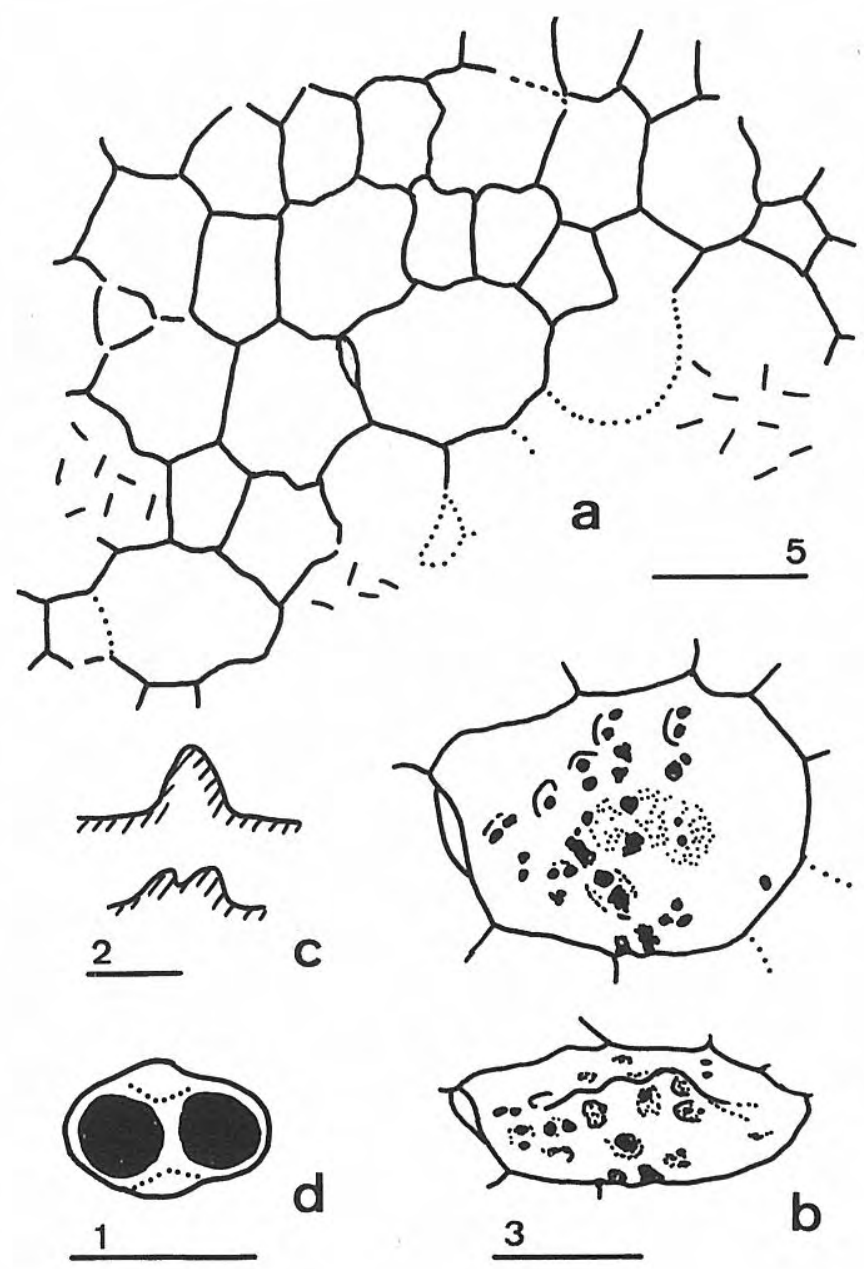

Figura 2. Sphaeronitida inc. fam. a, Contorno de las suturas de las placas en el fragmento de teca FBIIIB 1256 (cf. Lám. II, fig. 8); b, detalle de una gran placa del ejemplar anterior, en vista superior y oblicuo-lateral; c, perfil transversal de dos tubérculos; d, foseta diplopórica. Escala gráfica en milímetros.

Las fosetas diplopóricas son elípticas, con un borde saliente y dos poros separados por una barra transversa incipiente. Las fosetas mayores alcanzan $1 \mathrm{~mm}$ de longitud. La distribución de las fosetas en las placas es irregular, disponiéndose unas veces apretadas y otras muy separadas entre sí, si bien por lo general suelen concentrarse hacia el centro de las placas de modo que su margen periférico resulta bastante liso o sólo presenta algunas fosetas más pequeñas. Las fosetas mayores entallan netamente la base y los flancos de los tubérculos mamelonares, acentuando la irregularidad de la superficie externa de las placas. Pese a que no hemos reconocido ninguna traza segura de oclusión de las fosetas, las pequeñas protuberancias observadas corresponden sin duda a fosetas enmascaradas, por lo que cada foseta visible provendría posiblemente del desgaste de una pústula.

\section{Observaciones}

La presencia de tubérculos mamelonares recuerda al género Calix, si bien ninguna de sus especies presenta suturas curvas o sinuosas entre las placas. Este tipo de 
suturas ha sido descrito en Aristocystites bohemicus sinuosus (Chauvel, 1966), si bien las placas de esta forma norteafricana carecen de tubérculos. La presencia de tubérculos irregulares, semejantes a los del material estudiado, se conoce en ciertas especies berounienses de Destombesia $(D$. diedra acuta Chauvel, 1966; $D$. diedra ssp. Chauvel, 1969; D. hispanica Chauvel y Truyols, 1977). Sin embargo, las placas de las formas citadas son regularmente poligonales, no poseen suturas sinuosas, y sus fosetas se disponen radialmente.

Por todo ello, el material estudiado es insuficiente todavía para intentar siquiera una aproximación taxonómica a nivel de familia (¿Destombesiaidae, Aristocystitidae?)

CLASE RHOMBIFERA Zittel, 1879

ORDEN DICHOPORITA Jaekel, 1899, emend. Paul, 1968

Superfamilia HEMICOSMITIDA Jaekel, 1918

Familia Caryocrinitidae Bernard, 1895, emend. Frest, 1975

Género Caryocrinites Say, 1825

Especie tipo: Caryocrinites ornatus Say, 1825.

\section{Caryocrinites cf. rugatus (Forbes, 1848)}

Lám. I, fig. 3-4, 8-11

\section{Material estudiado}

9 placas aisladas, FB-IIIA 1257,1250; FB-IIIB 1251$1252,1253 \mathrm{~b}, 1261-1263$, procedentes de las "margas de briozoos" del Miembro Piedra del Tormo de la Formación Fombuena; Viniciense.

\section{Descripción}

Los ejemplares examinados consisten en placas penta a heptagonales, más largas que anchas $(14 \times 9,12 \times 9,11 \times 9$,
$11 \times 8 \mathrm{~mm}$ ), moderadamente convexas y recorridas por 5-7 crestas radiales agudas. En la base de cada una de estas últimas se observa un alineamiento de 8 a 12 poros, cuyas aperturas son algo salientes y resultan más notorias en tres de las crestas radiales. Los sectores comprendidos entre las crestas principales poseen una ornamentación prominente, formada por pequeños tubérculos o crestas cortas, que tienden a ordenarse en hileras paralelas a las suturas. No obstante, con gran frecuencia estos elementos pueden presentarse unidos entre sí de un modo irregular para dar crestas más largas y agudas de orientación radial, comarginal, curva o incluso ramificada.

\section{Observaciones}

La morfología y distribución de los poros revela que estas placas aisladas corresponden a un caryocrinítido, siendo las pentagonales placas infralaterales. Su ornamentación tan característica permite comparar nuestro material con $C$. rugatus (Forbes), una especie conocida previamente en el Ashgill de la Montagne Noire (SE de Francia) y señalada como posible en las Calizas de Cistideos de Aragón (Chauvel y Le Menn, 1979) y las Cadenas Costeras Catalanas (Meléndez y Chauvel, 1982). Su probable presencia en materiales más antiguos de la Formación Fombuena restaría a dicha especie gran parte de su valor bioestratigráfico.

Hemicosmitida inc. fam. Lám. I, fig. 12-18; Lám. II, fig. 9-10

\section{Material estudiado}

13 placas aisladas, FB-IIIA 1248a-b; 1249a-b, FB-IIIB 1253a, 1254, 1264-1271, CP-II 544 a-b, procedentes en su mayoría de las "margas de briozoos" de la base de la Formación Fombuena, excepto el último ejemplar citado, recogido en niveles correlacionables con los anteriores en las "Capas de Bronchales", Viniciense-Zahoraniense.

\section{Lámina I}

1 Aristocystitidae gen. et sp. indet. Réplica en látex de algunas placas gruesas mostrando los canales suturales. Formación Castillejo, Dobrotiviense. FB-V 42, x 2.4 .

2 Calix rouaulti Chauvel, 1936. Réplica en látex del polo aboral de la teca, mostrando ciclos regulares de tubérculos. Formación Castillejo, Dobrotiviense. Ejemplar FB-V 40, x 2.3.

3-4 y 8-11 Caryocrinites cf. rugatus (Forbes, 1848), Formación Fombuena, Viniciense. Réplica en látex de diversas placas aisladas: 3, ejemplar FB-IIIB 1261a (hexagonal y con elementos ornamentales menores que tienden a unirse en crestas radiales, curvas o ramificadas), x 4; 4, FB-IIIB 1252; 8, FBIIIA 1247 (placa pentagonal con crestas secundarias comarginales, radiales o ramificadas), x 3.6; 9, FBIIIB 1251, x 5; 10, FB-IIIB 1263, x 4; 11, FB-IIIB 1262 (placa heptagonal con gránulos unidos en crestas paralelas a las suturas), x 3.4.
5-6 Heliocrinites? isabellae (Meléndez, 1944). Holotipo, original de Meléndez (1944: lám. 15, fig. 5, fig. 25 en el texto). Molde interno de una teca en vista lateral (fig. 5) y oblicua-lateral (fig. 6). Formación Fombuena, Viniciense. FB-72, x 2.

7 Heliocrinites sp. Réplica en látex del molde externo de una teca incompleta. Formación Fombuena, Viniciense. FB-IIIB 1272, x 3.5.

12-18 Hemicosmitida inc. fam. Réplica en látex de diversas placas aisladas mostrando la ornamentación externa (12, FB-IIIB 1264, x 4.4; 13, FB-IIIB 1270a, x 4.8; 14, FB-IIIA 1248b, x 2.8; 16, CP-II 544a, x 3.7), y algunos moldes internos con canales tangenciales (15, FB-IIIB 1254, x 2.6; 17, CP-II 544b -cf. fig.16-, x 3.8; 18, látex de una placa parcialmente erosionada, FB-IIIB 1265, x 4.4). Fig. 12-15 y 18, Formación Fombuena; fig. 16-17, "Capas de Bronchales"; Beroun (Viniciense-Zahoraniense). 

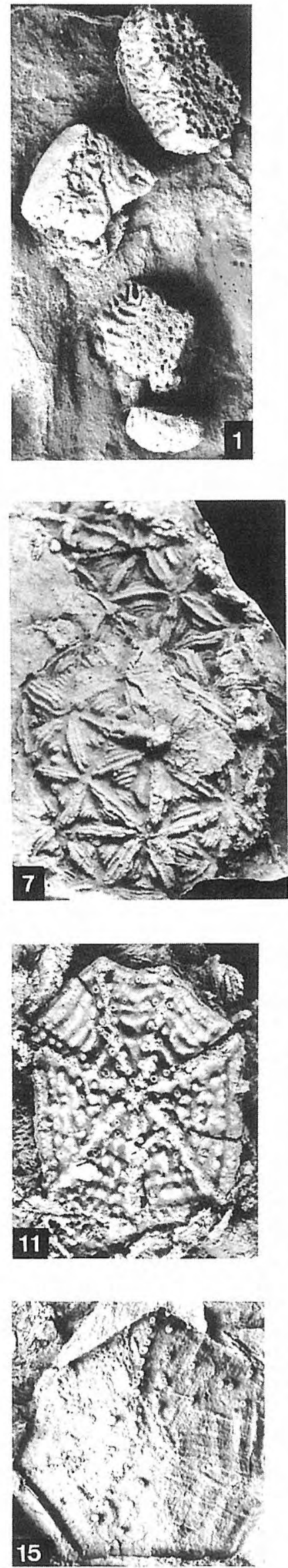
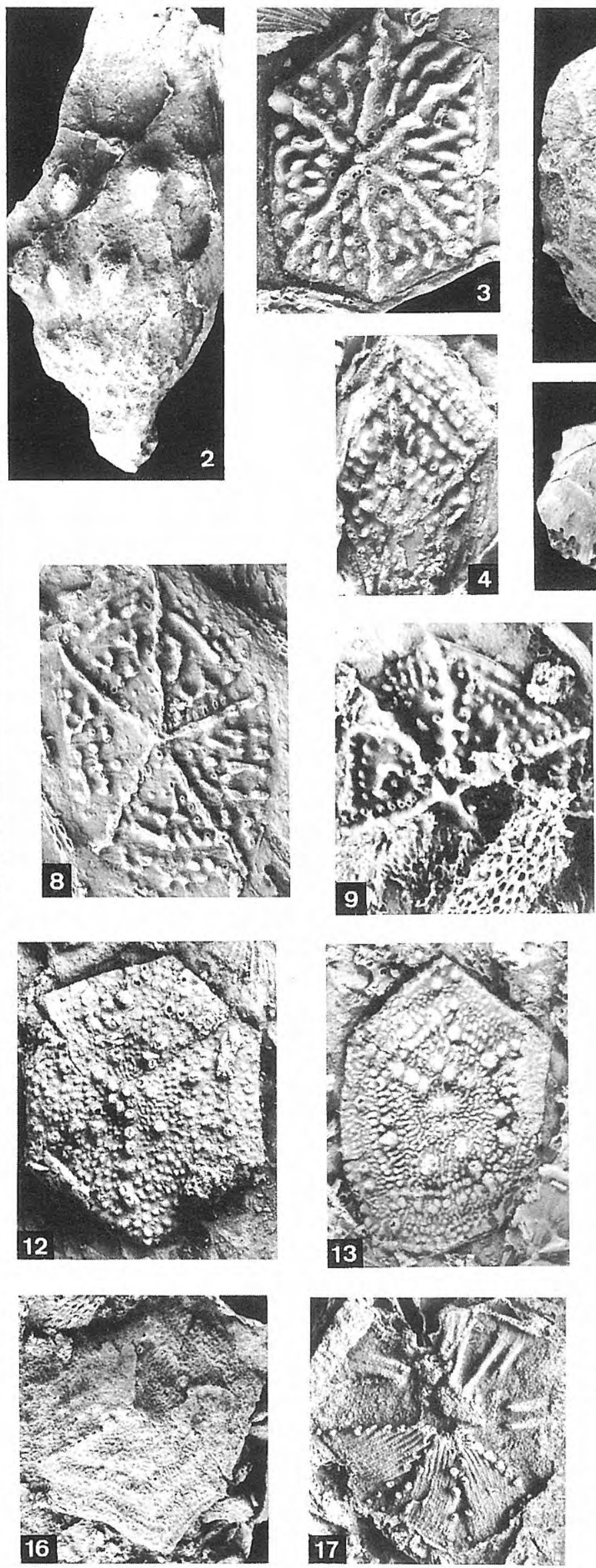

Lámina I
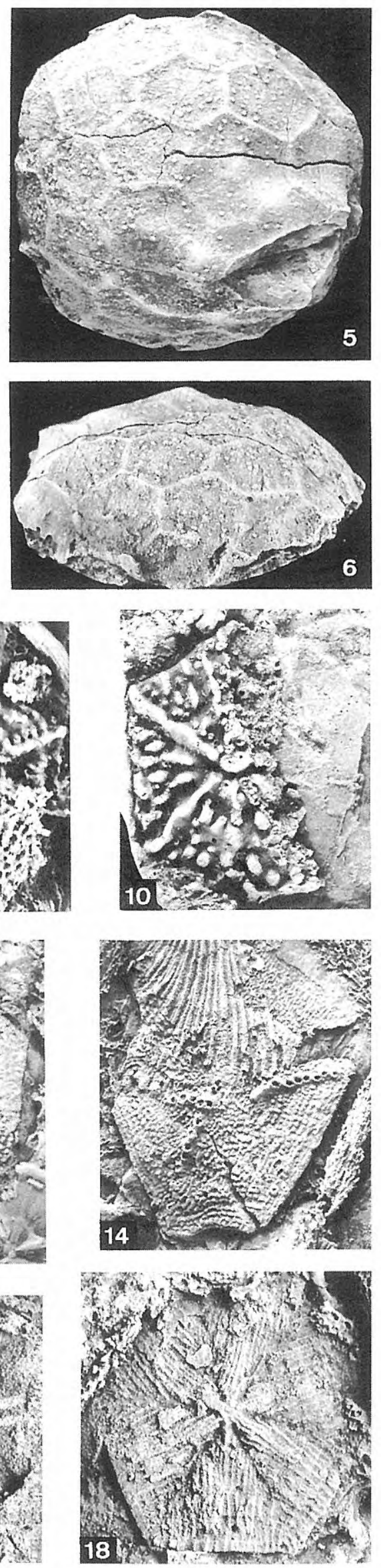

Revista Española de Paleontología, 11(1), 1996. 


\section{Descripción}

La mayor parte del material consiste en placas de contorno hexagonal, ornadas exteriormente por líneas granulosas de densidad variable, a veces combinadas con leves corrugaciones comarginales, y en las que resaltan filas radiales de poros en relieve. En el molde interno se observan numerosos canales tangenciales apretados, que normalmente forman parte de seis criptorrombos endotecales cuya diagonal menor coincide con las caras suturales de las placas (Lám. I, fig. 18). Sin embargo, el ejemplar CP-II 544a muestra solamente tres semirrombos completos en una de las mitades de la placa, mientras que en la otra aparecen algunos canales simples, aparejados y espaciados entre sí (Lám. I, fig. 17).

Otro morfotipo diferente agrupado en esta misma sección (FB-IIIB 1267-1269, 1253a, 1270a-b) comprende placas pentagonales, de dimensiones algo más reducidas y que por lo demás resultan idénticas a las anteriores, excepto que son claramente alargadas según un eje $(11 \times 7,9 \times 6,9 \times 7$, $8 \times 6 \mathrm{~mm}$ ) y en su superficie externa existen algunos gránulos más gruesos de tendencia radial (Lám. I, fig. 13).

Por último, una gran placa aislada e incompleta (FB-IIIA 1249a-b: longitud máxima $24 \mathrm{~mm}$ ) difiere del resto del material por presentar una superficie externa aparentemente lisa, ornada únicamente por las aperturas compuestas (cribosas: inhalantes) de los dicoporos integrantes de dos criptorrombos endotecales (Lám. II, fig. 9), cuyos tubos correspondientes se aprecian con claridad en el molde interno.

\section{Observaciones}

La ornamentación granulosa y la morfología de los rombos pectinados permite relacionar el material con la superfamilia Hemicosmitida, si bien no es posible aportar una identificación más detallada al poderse tratar tanto de Hemicosmites? como de Caryocrinites?. El desarrollo de criptorrombos en una de las mitades de la placa se observa también en algunas infralaterales de representantes de esta superfamilia (Kesling, 1968: S220-S223).

Material similar al que acabamos de describir ha sido reconocido también en las margas kralodvorienses con las que culminan las "Capas de Bronchales" en el Macizo del Tremedal (Fig. 3b), y en la Fm. Cabeço do Peão del sinclinal de Mação (Portugal). De este último punto estudiamos varias placas de la colección A. Marques Guedes (Lisboa), de edad comparable al material descrito.

\section{Superfamilia CARYOCYSTITIDA Jaekel, 1918 \\ Familia Caryocystitidae Jaekel, 1918 \\ Género Heliocrinites Eichwald, 1840}

Especie tipo: Echinosphaerites balticus Eichwald, 1829

\section{Heliocrinites sp. \\ Lám. I, fig. 7}

\section{Material estudiado}

Un ejemplar, FB-IIIB 1272, procedente de las "margas

\section{Lámina II}

1-5, 11 Rhombifera bohemica Barrande, 1867. Placas laterales aisladas procedentes de la Formación Fombuena, Viniciense. 1-2, FB-IIIB 1276a-b, molde interno de una placa L3 con parte de la superficie externa $(1, x 1.6)$, y réplica en látex de su cara interna lisa con medio pectinirrombo $(2, \mathrm{x}$ 1.5); 3 y 11, IL1 ó IL2, FB-III-B 1275a-b, molde interno de la cara externa $(3, x 1.4)$ y réplica en látex del mismo (11, x 1.3); 4, réplica en látex de una IL1 ó IL2 incompleta, FB-IIIB 1274, mostrando los dos pectinirrombos (x 2.5); 5, extremo inferior de una L5 visto por su cara interna, réplica en látex del ejemplar FB-IIIB 1277 , x 2.5 .

6 Rhombifera? sp. Réplica en látex de una placa, posiblemente B3 ó B4, procedente de las "Capas de Bronchales", Zahoraniense. CP-II 552, x 3.

7-8 y 16-17 Sphaeronitida inc. fam. Fragmentos tecales con placas en conexión, procedentes de la Formación Fombuena, Viniciense. 7, réplica en látex FB-IIIB 1260, x 2.4; 8, idem. del ejemplar FB-IIIB 1256, x $1.6 ; 16-17$, detalles del ejemplar anterior (16, molde interno mostrando placas con estrías de crecimiento , x 2.7; 17, molde externo con placas mamelonares de suturas sinuosas, y fosetas diplopóricas distribuídas irregularmente, x 2.6).

9-10 Hemicosmitida inc. fam. Placa aislada FB-IIIB 1249 mostrando aperturas compuestas (cribosas) en la superficie externa (fig. 9, réplica en látex, x
2.7), correspondientes a dos criptorrombos endotecales (fig. 10, molde interno mal conservado, x 1.9). Formación Fombuena, Viniciense.

12-13 y 18-19 Calix? sp. cf. C. gutierrezi Chauvel y Meléndez, 1986. Fragmentos tecales de dos ejemplares procedentes de la Formación Fombuena (FB-IIIB 1255: fig. 12-13) y las "Capas de Bronchales" (CP-II 546: fig. 18-19). En el primero se aprecian fosetas diplopóricas poligonales (réplica en látex de la superficie externa x 2.5 y x 5 respectivamente), mientras que el segundo consiste en un molde interno (fig. 18, x 1.3) en el que se indica con una flecha el área de la que procede una pequeña réplica en látex de la superficie externa (fig. 19, x 4: constatar la presencia de tubérculos y fosetas poligonales).

14 Aspecto general de la muestra FB-IV 1280 , procedente de la parte media de la Formación Fombuena, en la que se aprecian restos articulados de crinoides (un cáliz y un brazo con pínulas), junto a briozoos y una valva de braquiópodo (Rostricellula sp.).

15 Fragmento tecal de un equinodermo indeterminado, posiblemente un crinoide, procedente de las Capas de Bronchales, Beroun. Obsérvese la marcada ornamentación de las placas y la existencia de un "cordón" ramificado en relieve con crestas longitudinales. CP-II 549, x 3. 
Lámina II
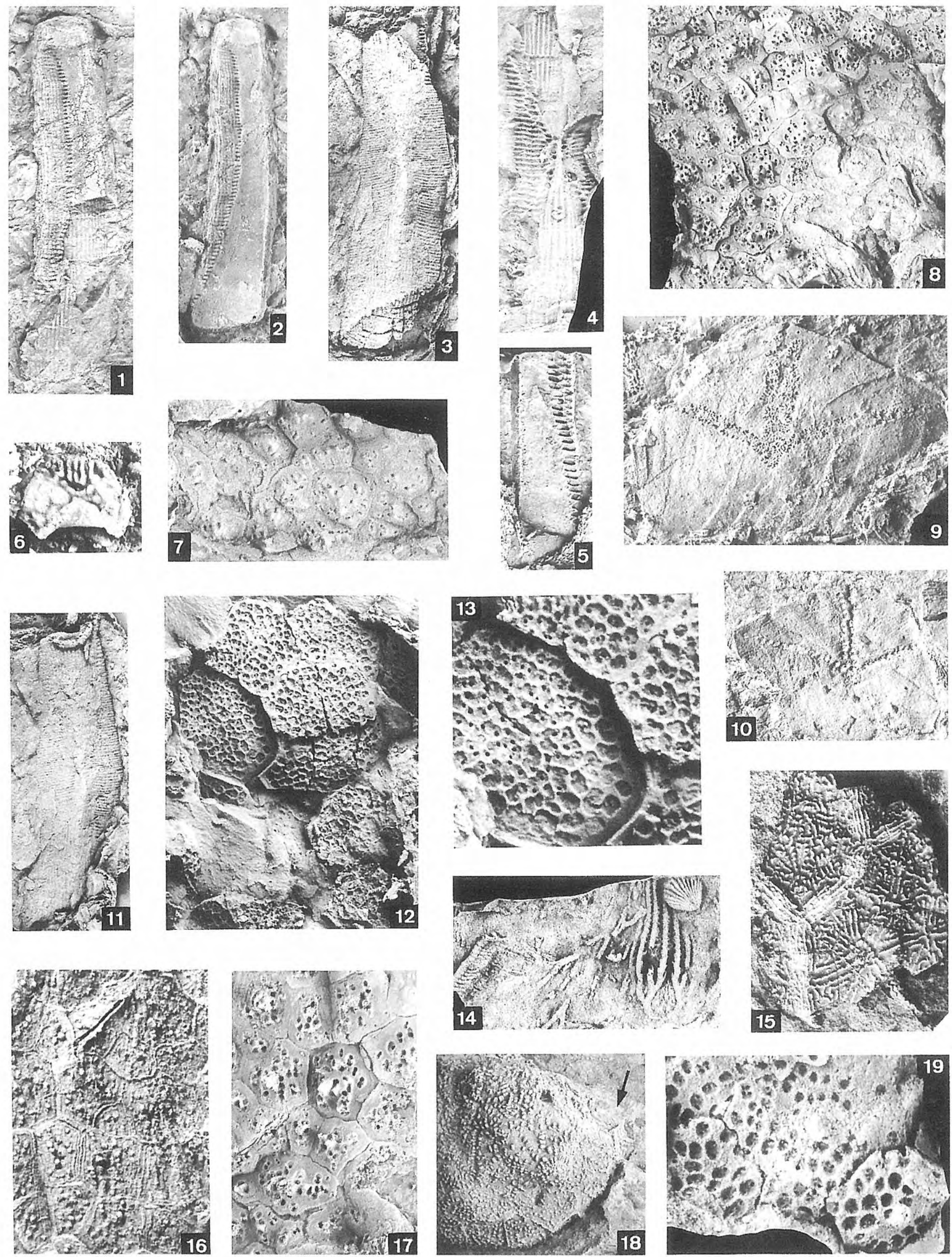

Revista Española de Paleontología, 11(1), 1996.

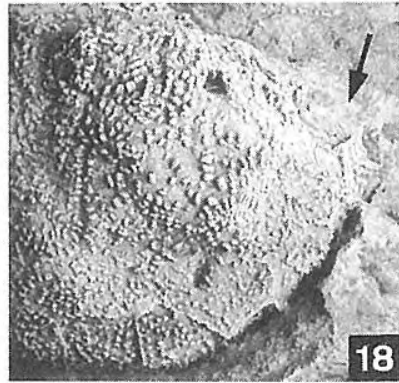


de briozoos" del Miembro Piedra del Tormo de la Formación Fombuena; Viniciense.

\section{Descripción}

El único ejemplar disponible consiste en el fragmento del molde externo de una teca globulosa y alargada, en el que se reconocen una docena de placas profusamente ornamentadas y dispuestas en 6 ciclos. Cada una de ellas posee 5-6 pliegues radiales fusiformes, que se continúan en los de placas adyacentes, de perfil longitudinal convexo. La degradación superficial del molde externo hace que la sección transversal de estas crestas varíe desde triangular con una arista viva, a presentar un surco longitudinal que delimita dos lamelas agudas. La longitud de los pliegues axiales es de unos $2 \mathrm{~mm}$ y no llegan a alcanzar el centro de las placas, por lo que la separación de centros entre placas contiguas es algo mayor $(2,5 \mathrm{~mm})$.

Los canales tangenciales son claramente compuestos: por un lado, en los pliegues radiales desgastados se observan hasta cuatro canales longitudinales petaloides cuya anchura conjunta es de $0,5 \mathrm{~mm}$; por otro, en cada uno de los flancos de estos mismos pliegues existen otros 3 a 4 canales rectilíneos y abultados, que se perciben claramente en el fondo de las áreas triangulares que delimitan los pliegues radiales.

\section{Observaciones}

La trama ornamental de la teca y sus canales tangenciales compuestos relacionan claramente nuestro material con el género Heliocrinites, si bien no existen datos suficientes para poder precisar su identidad específica. Tal vez la especie más próxima morfológicamente sea $H$. helmhackeri (Barrande, 1887), cuyos pliegues axiales son igualmente fusiformes y carecen de un centro de placas prominente. Esta forma ha sido descrita en el Viniciense de Bohemia y el Anti-Atlas marroquí (Chauvel, 1977), citada también en un horizonte de la misma edad en la Zona Centroibérica (Gutiérrez-Marco et al., 1992), y perdura durante el Ashgill en las Calizas de Cistideos de Aragón (Chauvel et al., 1975; Chauvel y Le Menn, 1979). Las relaciones del ejemplar estudiado con otras especies contemporáneas como H. tafilaltensis Chauvel, 1966, del Beroun de Marruecos, no pueden ser establecidas por insuficiencia de material, del mismo modo que, por las razones que apuntamos más adelante, tampoco pueda aclararse su eventual identidad con H.? sampelayanus (Meléndez, 1944) o H.? isabellae (Meléndez, 1944). No obstante, el hallazgo de este único ejemplar seguro de Heliocrinites en la Formación Fombuena, proporciona un mayor crédito a la revisión genérica de las dos últimas especies mencionadas, procedentes de los mismos niveles del Miembro Piedra del Tormo. Por lo tanto, las "margas de briozoos" constituyen el horizonte más antiguo con Heliocrinites en la Península Ibérica. La mayor abundancia y diversidad del género en el Ordovícico mediterráneo, corresponde claramente al Bohdaleciense y Kralodvoriense de Argelia, Bélgica, España (Aragón, Cataluña y Sierra Morena), Francia (Macizo Armoricano, Montaña Negra y Pirineos), Italia (Cerdeña), Marruecos y Portugal.

\section{Heliocrinites? isabellae (Meléndez, 1944) Lám. I, fig. 5-6}

$v^{*} 1944$ Aristocystites Isabellae n.sp.- Meléndez, 101-102, lám. 15, fig.5, fig. 25 en el texto.

\section{Material estudiado}

Holotipo FB-72 (por monotipia), original de Meléndez (1944: lám.15, fig. 5). Procede de las "margas de briozoos" del Miembro Piedra del Tormo de la Formación Fombuena, localidad FB-IIIB; Viniciense.

\section{Descripción}

El ejemplar estudiado consiste en el molde interno de un fragmento tecal de contorno subcircular (diámetro aproximado: $25 \mathrm{~mm}$ ), correspondiente a una teca de morfología globulosa. Se reconocen una veintena de placas poligonales dispuestas con bastante regularidad, de 5 a 7 lados, y de las cuales la mayor mide aproximadamente $8 \mathrm{~mm}$. En su interior se distinguen numerosos moldes de canales cuya disposición parece irregular, pero que a veces están agrupados en los bordes de las placas o en líneas radiales, denotando la presencia de dicoporos dispuestos en rombos.

Las suturas entre placas no desgastadas muestran un perfil elevado y convexo, correspondiendo a un abultamiento del molde interno perpendicular a la sutura.

\section{Observaciones}

La forma de la teca y la disposición de las placas relacionan el ejemplar tanto con Echinosphaerites como con Heliocrinites. Sin embargo, las suturas de perfil convexo se conocen tan sólo en Heliocrinites tafilaltensis Chauvel, una especie del Beroun de Marruecos (Chauvel, 1966, 1977). La comparación con la misma permite adscribir provisionalmente la forma ibérica al género Heliocrinites, si bien se necesitaría un material más completo para poderlo asegurar. Dado que el holotipo de H.? isabellae (Meléndez) presenta pocos caracteres diagnósticos que permitan asignar con las suficientes garantías cualquier nuevo material a la especie, y pese a que ésta fue descrita originalmente de un modo taxonómicamente válido, proponemos restringir la misma al único ejemplar conocido para evitar futuras especulaciones que pongan en peligro la estabilidad nomenclatural.

\section{Heliocrinites? sampelayanus (Meléndez, 1944)} Fig. 3a

v*1944 Caryocystites Sampelayanus n.sp. - Meléndez, 100101, lám. 15, fig. 6; fig. 24 en el texto.

\section{Material estudiado}

Holotipo MGM-337-O (por monotipia), original de Meléndez (1944, lám. 15, fig. 6). Procede de las "margas de briozoos" del Miembro Piedra del Tormo de la Formación Fombuena, localidad FB-IIIB; Viniciense.

\section{Observaciones}

El ejemplar estudiado consiste en el molde externo de una teca aplastada, de aproximadamente $16 \mathrm{~mm}$ de diámetro, cuyas placas presentan 5-6 costillas radiales 
finas, muy erosionadas, conectadas con las de placas adyacentes a través de las caras suturales (no las aristas). Este carácter puede indicar su posible relación con el género Heliocrinites, difícil de confirmar por el mal estado de conservación del ejemplar. Dado que por tratarse del holotipo no es posible adscribir con seguridad nuevo material a la especie, proponemos restringir el taxón a este único ejemplar, del mismo modo que hicimos con H.? isabellae (Meléndez), procedente de idéntica localidad y nivel estratigráfico. Este proceder ha sido adoptado también para otros muchos taxones de trilobites, braquiópodos, moluscos y briozoos descritos en forma válida en el Ordovícico del SO de Europa, pero mal caracterizados en los trabajos originales respectivos, gran parte de los cuales fueron publicados en el siglo pasado y cuyo material se perdió posteriormente, de modo que tampoco es posible acordar la designación de un nuevo ejemplar (lectotipo o neotipo).

El holotipo de $H$.? sampelayanus ha sido redescubierto, junto a una parte significativa del material original de Meléndez (1944), en el Museo Geominero, donde permanecía identificado como "Lophocystites sampelayanus (Mel.)".

\section{Superfamilia GLYPTOCYSTITIDA Bather, 1900 Familia Rhombiferidae Kesling, 1962 Género Rhombifera Barrande, 1867}

Especie tipo: Rhombifera bohemica Barrande, 1867.

\section{Rhombifera bohemica Barrande, 1867 Lám. II, fig. 1-5, 11}

\section{Material estudiado}

5 placas aisladas de gran tamaño, FB-IIIB 1274-1278, procedentes de las "margas de briozoos" del Miembro Piedra del Tormo de la Formación Fombuena, Viniciense.

\section{Descripción}

La placa de mayor tamaño, FB-IIIB 1275a-b, es una lateral inferior IL1 ó IL2 (nomenclatura de Kesling, 1968), que mide $47 \mathrm{~mm}$ de longitud y $13 \mathrm{~mm}$ de anchura a nivel de su mitad superior (en dirección oral). Su contorno general es trapezoidal alargado, y la sección, subtriangular, con la máxima altura $(5 \mathrm{~mm})$ localizada en el centro y a lo largo de una arista que recorre longitudinalmente la placa. En las dos caras laterales que delimitan esta arista se observan sendos semirrombos muy alargados, correspondientes a los rombos pectinados característicos de estos hidrofóridos, y que presentan una ornamentación a base de estrías transversas, limitadas hacia el interior de la placa por una hilera simple de poros. Sus aberturas son subcirculares en la cara externa de la placa (pectinirrombos disyuntos), y ranuras transversas en su cara interna. El resto de la superficie externa al rombo presenta una ornamentación constituída esencialmente por estrías longitudinales.

La placa FB-III 1274 posee unas características similares a la anterior pero dimensiones más reducidas $(7 \mathrm{x}$ $27+\mathrm{mm}$ ). La configuración de los pectinirrombos permite identificarla también como una placa lateral IL1 o IL2 de la pirámide inferior de la teca.
El ejemplar FB-IIIB 1276a-b consiste en una placa lateral comprimida y conservada por su cara interna, si bien en la pieza FB-IIIB 1276 b parte de la placa se ha perdido, apreciándose el molde de la superficie externa con su estriación longitudinal característica (Lám. II, fig.1). El contorno general de la placa es subtrapezoidal a subrectangular alargado (43 x 9,5 mm), con el extremo más ancho recto y el opuesto arqueado a ligeramente acuminado.

El carácter más sobresaliente es la existencia de medio rombo pectinado alargado en uno de los laterales de la placa, cuya configuración (más ancho y redondeado en sentido oral, y más oblicuo en sentido aboral, donde intersecta en ángulo agudo el margen postero-lateral) permite identificar la placa como una lateral superior L3. La superficie interna de la placa es lisa, mientras que el rombo pectinado muestra una estriación transversa que desemboca en una hilera de poros elípticos, combinada con 5 ó 6 estrías longitudinales que le confieren un aspecto reticulado.

Por último, los ejemplares FB-IIIB 1277 y 1278 corresponden a la extremidad de articulación de sendas placas laterales, probablemente la superior L5 en un caso (1277) y no pudiéndose determinar en el otro. En la primera se aprecia la superficie interna lisa y el extremo aboral de medio rombo pectinado con sus características ranuras transversas. La anchura basal de esta placa es $5 \mathrm{~mm}$. El otro ejemplar (1278) consiste en un molde externo, con la típica estriación longitudinal y el arranque de medio rombo pectinado, cuya posición y características lo relacionan con una placa lateral superior L3 o una inferior IL5.

\section{Observaciones}

Pese a disponer solamente de placas aisladas, nuestro material corresponde claramente a un cistideo glyptocistítido de teca extremadamente alargada, formada por dos ciclos de placas laterales, alineados verticalmente y conectados por sus extremos más anchos y obtusos, entre los que se disponen rombos pectinados también muy alargados. Estos caracteres son exclusivos del género Rhombifera Barrande, entre cuyas especies los detalles observados concuerdan con los de la forma checa $R$. bohemica Barrande, 1867, y difieren notablemente de $R$. matteii Renard, 1967, descrita en el Bohdaleciense de la Montagne Noire francesa. En este sentido, las placas laterales L3, L5 y el fragmento de L3 o IL5 descritos, muestran cada una medio rombo pectinado, mientras que en la especie gala todas las placas laterales (L1 a 5, IL1 a 3) poseen un par de semirrombos. De igual modo, las placas laterales inferiores son mucho menos alargadas que en la forma bohemo-ibérica, desplazándose la anchura máxima de los rombos pectinados hacia un punto mucho más bajo (sentido aboral) de dichas placas infralaterales (cf. Renard, 1967: fig. 1).

Aparte del material descrito, consistente en restos de 5 placas laterales, entre nuestros ejemplares destaca un resto enigmático de equinodermo (CP-II 552: Lám. II, fig. 6) que por su morfología y dimensiones podría corresponder a una placa basal (B3 o B4) de la teca de Rhombifera. Sin embargo, ello no puede asegurarse hasta disponer de ejemplares articulados en buen estado de conservación, por lo que no ha sido incluída en la descripción anterior. 


\section{Distribución}

$R$. bohemica es un extraño cistideo descrito originalmente en las Formaciones Vinice y Zahorany (Beroun) de Bohemia (Barrande, 1867, 1887; Kesling, 1962), aunque también ha sido mencionado en las Formaciones Liben̆ y Letná en la misma área (Havlícek y Vaněk, 1966). Fuera de la República Checa, la especie había sido citada únicamente en el Ordovícico superior de Amêndóa, Portugal (Delgado, 1908: pág. 83), por lo que nuestro trabajo confirma su presencia en la Península Ibérica y constituye la primera descripción de dicha forma en España. Rhombifera sp. fue identificada previamente en las "Pizarras Intermedias " del Zahoraniense de los sinclinales de Guadarranque y Santa Lucía (Cáceres: Ballestra et al., 1982; Gil Serrano, 1985), y en un afloramiento tectonizado de la Formación Fombuena situado en las Cadenas Ibéricas Occidentales, donde Wolf (1976 inédito) describió una teca diminuta y articulada con sus ciclos de placas orales (Wolf, op. cit., pág. 102, lám 3, fig. 9).

La especie $R$. bohemica sin duda existe en Portugal, en las pizarras del Miembro Queixoperra de la Fm. Cabeço do Peão del sinclinal de Mação (sur de la Zona Centroibérica), donde pudimos identificar recientemente tres placas laterales a partir del material conservado en la colección del Dr. A. Marques Guedes (Lisboa). Los mismos niveles contienen abundantes briozoos, trilobites, braquiópodos, moluscos, equinodermos, cornulítidos y machaeridios referibles al Viniciense(?)-Zahoraniense.

La presencia de Rhombifera en la Cordillera Ibérica reviste el interés añadido de confirmar para los equinodermos las relaciones biogeográficas con Bohemia observadas por Villas (1985) entre los braquiópodos articulados presentes en los mismos niveles de la Formación Fombuena. El hallazgo de especies comunes de braquiópodos y equinodermos entre ambas regiones, permite correlacionar al menos el Miembro Piedra del Tormo con el piso Viniciense de Bohemia (Villas, 1992).

\section{CLASE BLASTOIDEA Say, 1825 SUBCLASE CORONATA Jaekel, 1918}

\section{Observaciones}

Los coronados constituyen un grupo reducido pero muy característico de equinodermos pelmatozoos, exclu- sivamente ordovícico-silúricos, que tradicionalmente fueron considerados como crinoides o bien como blastoideos primitivos. En ambos casos se les asignaba un rango de orden dentro de las clases correspondientes, cuya denominación induce a la confusión con el orden Coronata Maass, 1903 (Cnidaria, Schyphozoa), si bien Brett et al. (1983) erigieron más tarde para estos equinodermos la nueva clase Coronoidea, resaltando sus diferencias frente a otras clases mencionadas.

Sprinkle $(1973,1980)$ indicó una posible derivación de los blastoideos y parablastoideos a partir de los eocrinoides, en los que reunió tambien a los coronados. Paul (1977) sugirió que los blastoideos debieron tener su origen en los rombíferos, con lo cual el antecesor de los coronados pasó a ser, de nuevo, fuente de especulación (Broadhead, 1982). No obstante, Sprinkle (1995) admite la posibilidad de que los coronados, en tanto que "grupo precursor" entre los blastozoos, pueden clasificarse mejor con sus descendientes en lugar de con sus antecesores eocrinoides, que formarían así parte integral de la llamada "Fauna Cámbrica" desde el punto de vista evolutivo.

En el presente trabajo nos sumamos a la opinión de Donovan y Paul (1985) y Paul (1988), quienes argumentaron convincentemente las relaciones filéticas de coronados y eublastoideos, discutiendo su origen y proponiendo la unificación de aquéllos, junto con los blastoideos y el enigmático Lyssocystites, en una Clase Blastoidea ampliada y redefinida. Los mismos trabajos explican también la terminología y medidas estándar adoptadas en este estudio.

Familia Stephanocrinidae Wachsmuth y Springer, 1886 Género Mespilocystites Barrande, 1887

Sinónimo: Mespilocystis Bather, 1900.

Especie tipo: Mespilocystites bohemicus Barrande, 1877, del Beroun (Letnaiense a Zahoraniense) de Bohemia (República Checa).

Diagnosis (según Paul, 1985)

Género de Stephanocrinidae caracterizado por la

\section{Lámina III}

1-5 y 8-17 Mespilocystites lemenni n. sp. Réplica en látex de diversas tecas procedentes de la Formación Fombuena (fig. 3, 14-15, Mb. Piedra del Tormo; 13, 17, Mb. Huerva) y las "Capas de Bronchales" (fig. 1-2, 4-5; 8-12, 16), Beroun. Fig. 1, 2 y 9, Holotipo CP-II 530, en vista lateral (1, x 5.2), oblicua-lateral (2, estereopar, x 5.5.) y oral $(9, \mathrm{x}$ 5.5.); 3, FB-IIIB 4321 en vista lateral (x 7); 4, 8, 12, ejemplar CP-II 541 en vista oblícua (4, x 5.5), oral $(8, x 6.6)$ y lateral $(12, x$ 7); 5, CP-II $555(\mathrm{x}$ 6.4); 10-11, CP-II 553 (10, x 4.7; 11, x 5); 13, 17, FB-VI 1279 (x 7); 14-15, FB-IIIB 1273 en vista oral $(14$, con placas ambulacrales) y lateral (15), ambas x 10; 16, CP-II 551 (x 7). En las figuras 8, 9 y 14, la flecha señala la posición del ano en la base del proceso interradial CD.

6-7 Stephanocrinidae indet. (Stephanoblastus? o forma juvenil de Mespilocystites?), de la unidad de areniscas calcáreas del Beroun del sinclinal del Valle (Cazalla de la Sierra, Sevilla). Ejemplar en vista lateral (6) y dorsal (7), ambas x 10 , figurado por Gutiérrez-Marco et al. (1984b: lám. 2, fig. 10-11). 
Lámina III
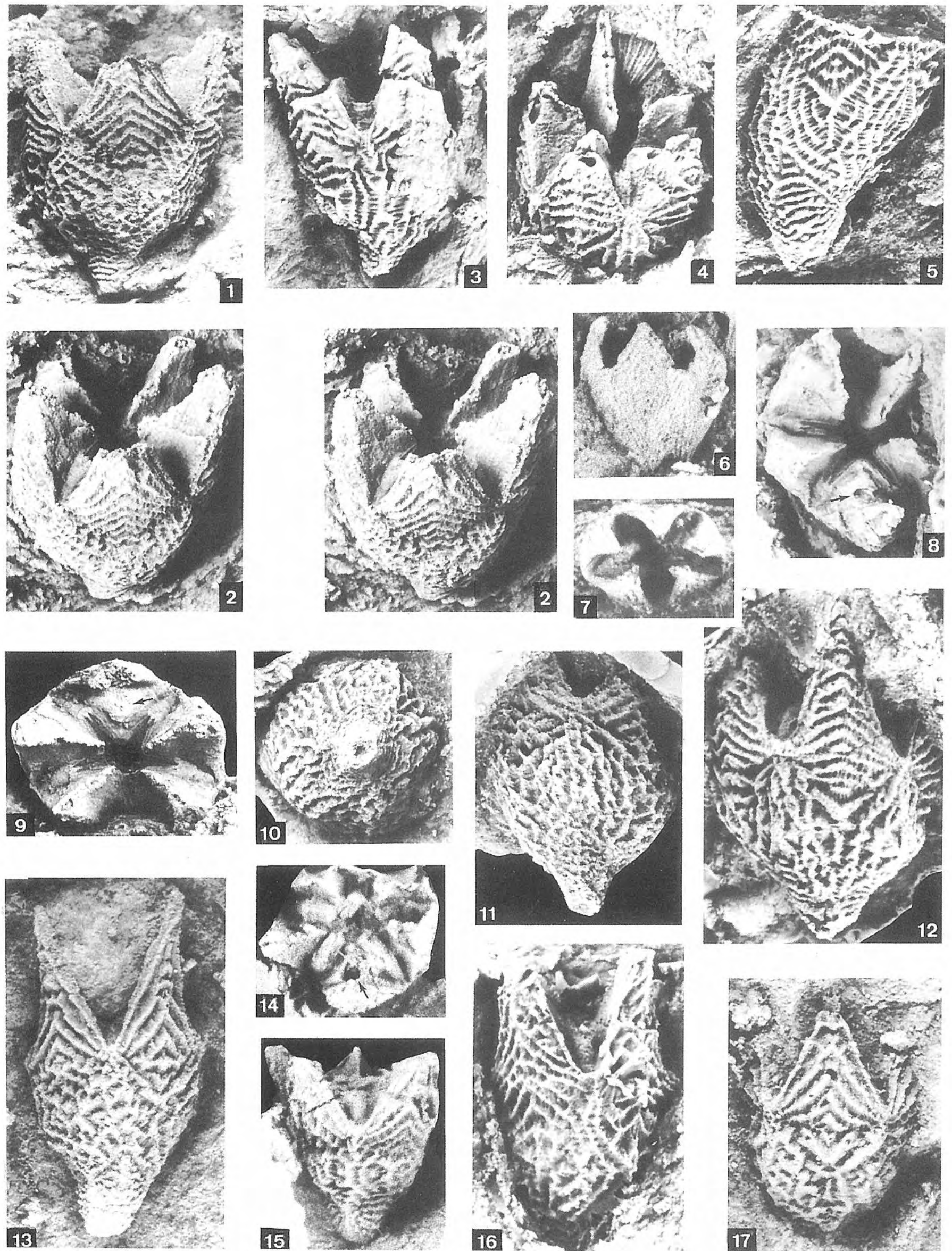

Revista Española de Paleontología, 11(1), 1996. 

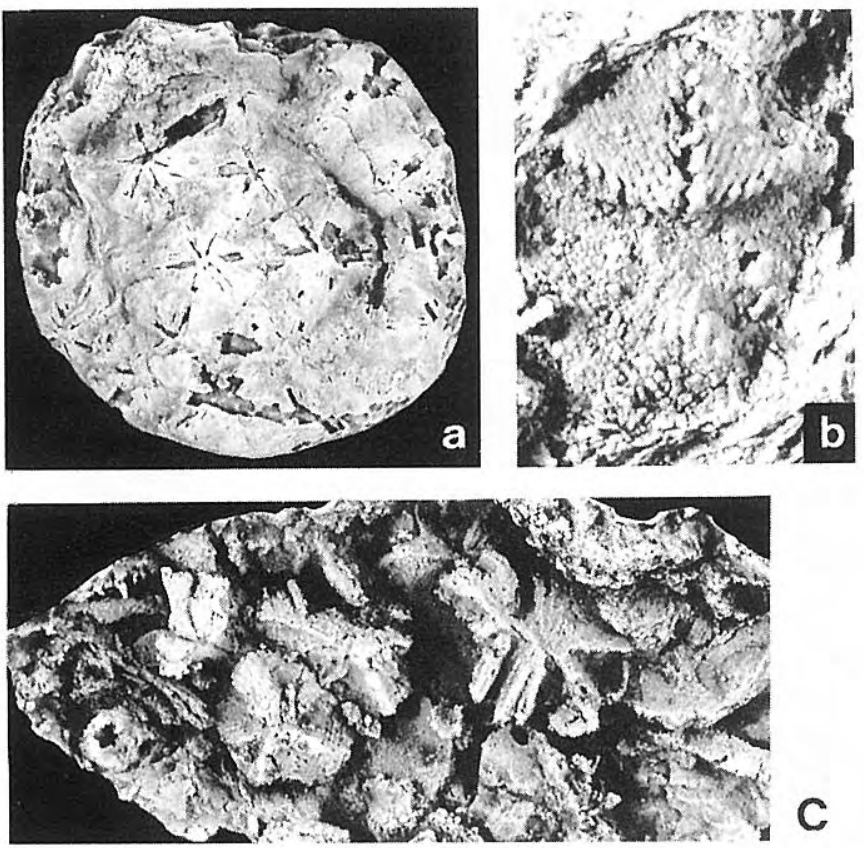

Figura 3. a, Heliocrinites? sampelayanus (Meléndez, 1944), holotipo de la especie, MGM-337-O, x 2,7; b, Hemicosmitida inc. fam., molde interno de una placa en el que se aprecian los canales tangenciales de los criptorrombos, NO-6300, $\mathrm{x}$ 6.4; c, Carycocystitida? indet., fragmento de una teca con placas desarticuladas, CHE-6301, x 2.5.

posesión de una teca cónica baja, procesos coronales erectos y surcos radiales geniculados.

\section{Especies asignadas}

Además de su especie tipo, $M$. tregarvanicus Le Menn, 1972, del Bohdaleciense-Kralodvoriense(?) del Macizo Armoricano francés, República Checa y España (Cordillera Ibérica); y M. lemenni n. sp., del Viniciense-Zahoraniense de la Cordillera Ibérica, zona Centroibérica española y Portugal?. El género podría estar representado además en el Kralodvoriense(?) de la zona Centroibérica portuguesa ( $M$. bussacensis Delgado, 1908: nomen nudum), y en el Kosoviense de Bohemia (Havlícek y Vanèk, 1966).

El ejemplar identificado como Mespilocystites sp. por Gutiérrez-Marco et al. (1984b: lám. 2, fig. 10-11), procedente del Beroun del $\mathrm{N}$ de Sevilla, puede no corresponder a este género pues, a diferencia del mismo, muestra procesos coronales cortos y dirigidos hacia dentro; surcos radiales planos de sección en forma de $\mathrm{V}$ carentes de geniculación; y la teca presenta una base obtusa y trirradiada. Estos detalles han podido advertirse gracias al hallazgo de nuevo material en la misma localidad cuyos caracteres, como los que acabamos de mencionar, lo relacionan muy probablemente con el género Stephanoblastus Jaekel, 1918. Las especies del mismo se distribuyen por el momento en el Ordovícico superior de Suecia y el Silúrico de la República Checa. Otros ejemplares comparables posiblemente con la forma sevillana de Stephanoblastus?, han sido identificados recientemente por uno de los autores (J.C. Gutiérrez-
Marco) en las calizas de Portilla de Luna (León: Kralodvoriense de la Zona Cantábrica), a través de un material aportado por el Dr. C. Aramburu (Univ. de Oviedo). No obstante, las diferencias observadas en el ejemplar sevillano podrían interpretarse también como de naturaleza ontogenética, pudiendo tratarse de una forma juvenil de Mespilocystites? sp. de ornamentación afín a la de $M$. tregarvanicus Le Menn.

\section{Distribución}

El género Mespilocystites ha sido registrado en el Beroun de la República Checa y la Península Ibérica, en el Kralodvoriense franco-español y en el Kosoviense checo, pudiendo estar representado eventualmente también en Portugal.

\section{Mespilocystites lemenni Gutiérrez-Marco n. sp.} Fig. 4a-h; Lám. III, fig. 1-5, 8-17

\section{Derivación del nombre}

La especie está dedicada al Dr. Jean Le Menn (Université de Bretagne Occidentale, Brest), quien describió los primeros Coronata del Ordovícico ibero-armoricano.

\section{Holotipo}

Fragmento de teca CP-II 530 con región oral y procesos coronales completos, $\mathrm{n}^{\circ}$ de catálogo MGM-957-O en la colección de fósiles españoles de invertebrados del Museo Geominero (ITGE, Madrid). Se ilustra aquí en la Lám. III, fig. 1-2,9, y en las Fig. $4 d$ y 4 h en el texto.

\section{Localidad tipo}

$2.150 \mathrm{~m}$ al OSO de Bezas (Teruel), en el talud septentrional de un pequeño camino que parte en dirección SO de la carretera local Bezas-Valdecuenca hacia el paraje denominado "El Vallejo" (Hoja n ${ }^{\circ} 589$, coordenadas Lambert X=798,580; Y=638,578). Punto CP-II, Macizo del Collado de La Plata, Rama Castellana de la Cordillera Ibérica.

\section{Estrato tipo}

Niveles arenosos con briozoos y braquiópodos en las "Alternancias del Caradoc" (="Capas de Bronchales"), cerca de su contacto tectónico con la Cuarcita Armoricana. Viniciense-Zahoraniense, Biozona de Svobodaina armoricana.

\section{Paratipos}

De la localidad tipo proceden una teca completa (CP-II 541a-b) y fragmentos de otros 5 ejemplares (CP-II 551, 553, 554, 555, 6302); el punto FB-IIIB (margas de Briozoos, Mb. Piedra del Tormo, Fm. Fombuena) ha suministrado dos tecas (FB-IIIB 1273 y 4321); y, finalmente, del Miembro Huerva de la Formación Fombuena (localidad FB-VI) poseemos una teca completa (FB-VI 1279a-b).

\section{Diagnosis}

Teca ancha en forma de copa, de sección redondeada a subpentagonal a nivel de la superficie oral, con base 
circular y región aboral estrecha y protuberante. Procesos coronales erectos y prominentes, representando casi la mitad de la altura de la teca. Ornamentación constituída por crestas gruesas, distribuídas entre placas contiguas siguiendo un patrón rómbico, entre las que se disponen otras crestas transversas más finas y numerosas, de orientación comarginal a las placas radiales y basales.

Cup-shaped theca, rounded-pentagonal in cross section, with narrow protruding circular base; the prominent distally directed coronal processes project only slightly outwards; the aboral ends of the radial furrows are inclined at about $25-30^{\circ}$. The distinctive coarse-ribbed ornament forms rhombic patterns across the plate sutures and is combined with finer ridges or striae, which are comarginal to the radial and basal plates.

\section{Descripción}

La teca tiene forma de copa con el extremo basal afilado y constreñido. Su altura en los ejemplares estudiados oscila entre 4 y $9,5 \mathrm{~mm}$, de los que más de la tercera parte corresponde a los procesos coronales. La achura máxima observada (6-7 mm) se alcanza a un nivel comprendido entre la base y los extremos distales de los procesos coronales, dependiendo del estado de conservación del material. La sección transversal de la teca es redondeada en su porción inferior y zonas inmediatas al polo aboral, pero hacia arriba pasa a ser claramente subpentagonal, tal y como se observa en vista oral.

El polo aboral muestra una faceta columnar estrecha y de contorno circular, con una depresión central subtriangular que denota la unión de tres placas basales. El diámetro externo basal representa tan sólo la sexta parte del diámetro de la teca a nivel oral, indicando la existencia de un pedúnculo comparativamente muy estrecho del que no se conservan placas columnares.

Los surcos radiales son relativamente anchos y de sección transversal en forma de $\mathrm{V}$ (ángulo de divergencia: $40-50^{\circ}$ ); a medio camino entre la boca y la periferia de la teca presentan una geniculación muy neta, que se traduce en una inflexión desde la horizontal (sector oral) hasta un ángulo de $25-30^{\circ}$. Con esta inclinación frente a la horizontal desciende el tramo más externo de cada surco, que presenta en la misma posición una cresta redondeada que se estrecha hacia la periferia sin llegar a alcanzar el punto de arranque de los procesos coronales.

Los surcos ambulacrales irradian horizontalmente desde la boca y muestran unas facetas periféricas netas para la inserción de las placas ambulacrales (Fig. 4f-g). Cada surco termina distalmente en un par de ranuras alimenticias que se apoyan en el sector adoral del genículo radial. La fina cresta que separa ambas ranuras tiende a prolongarse en sentido bucal por el fondo del surco ambulacral, coincidiendo con la sutura deltoidea, pero se atenúa antes de alcanzar la boca. Esta última tiene un perímetro subpentagonal redondeado.

Los procesos coronales son prominentes, presentándose dirigidos hacia arriba y ligeramente hacia fuera. Su longitud máxima representa más de $1 / 3$ de la altura total de la teca. Cada uno de los procesos es rómbico en sección transversal, formando sus caras externas redondeadas un ángulo obtuso, mientras que sus superficies adorales se unen en ángulo agudo. Estas últimas caras son lisas y en su arista interna de unión presentan a veces una ranura, que puede corresponder tanto a la sutura de las placas radiales, como a posibles aperturas en la cavidad celómica de los procesos coronales. Algunos ejemplares muestran también en posición central, dentro de las citadas superfices adorales, un leve surco longitudinal que por su situación debe corresponder a la sutura entre las placas radiales y deltoideas. El proceso interradial CD se diferencia bien de los cuatro restantes que acabamos de describir, por presentar una sección mucho más aplanada (Lám. III, fig. 8-9), ya que en la base de su cara adoral se sitúa una plataforma triangular subdeltoidea que posee un relieve distintivo. En ésta y adyacente al proceso coronal se localiza el orificio anal, mientras que en el extremo opuesto y a un nivel inferior se sitúa el hidroporo en forma de un pequeño tubérculo, próximo a la boca y sobre una superdeltoidea muy estrecha (Fig. 4f).

En ninguno de los ejemplares disponibles se han conservado las braquiolas. Sin embargo, en la parte distal de uno de los tractos ambulacrales aparejados del holotipo (surco radial $\mathrm{C}$ ), se observa una faceta amplia y aparentemente no dividida, de contorno elíptico, que podía servir de inserción a un tronco braquiolar grueso y ramificado como el que se conoce en otros Coronata.

De las placas que recubren la región oral de la teca sólo se conservan vestigios en el ejemplar FB-IIIB 1273 (Lám. III, fig. 14-15). Éste muestra en cada radio un par de placas ambulacrales alargadas, que recubren los surcos correspondientes a nivel de sus ranuras alimenticias.

La ornamentación de la teca es muy particular y está formada por crestas prominentes que tienden a disponerse en rombos, con un patrón tanto más regular, cuanto mayor es su altura en la teca y los procesos coronales. Entre crestas principales paralelas o contiguas, se observan también otras crestas o estrías transversas más finas y numerosas, cuya orientación resulta comarginal a las placas basales y radiales (Fig. 4a-e).

La ornamentación tan acusada de la teca, y la mala conservación de sus regiones orales, impide apreciar los límites de las placas que componen la cápsula dorsal. Lo único que cabe señalar es el punto triple de unión entre dos radiales y una braquial, que se traduce externamente en un elemento ornamental en forma de Y, cuyas bisectrices corresponden a las suturas de las placas tal y como denotan las estrías de crecimiento.

\section{Relaciones y diferencias}

La presencia de procesos coronales prominentes y surcos radiales fuertemente geniculados, relaciona claramente nuestro material con el género Mespilocystites. Dentro del mismo, la forma más próxima a la nueva especie es $M$. bohemicus Barrande, al que recuerda por el aspecto general de la teca, los largos procesos coronales y un patrón ornamental semejante. Sin embargo, la especie bohémica difiere en la posesión de una teca cónica amplia, con procesos coronales mucho más divergentes, de modo que la máxima anchura tecal excede bastante al diámetro oral y se sitúa con claridad a nivel de los extremos distales de aquéllos (cf. 

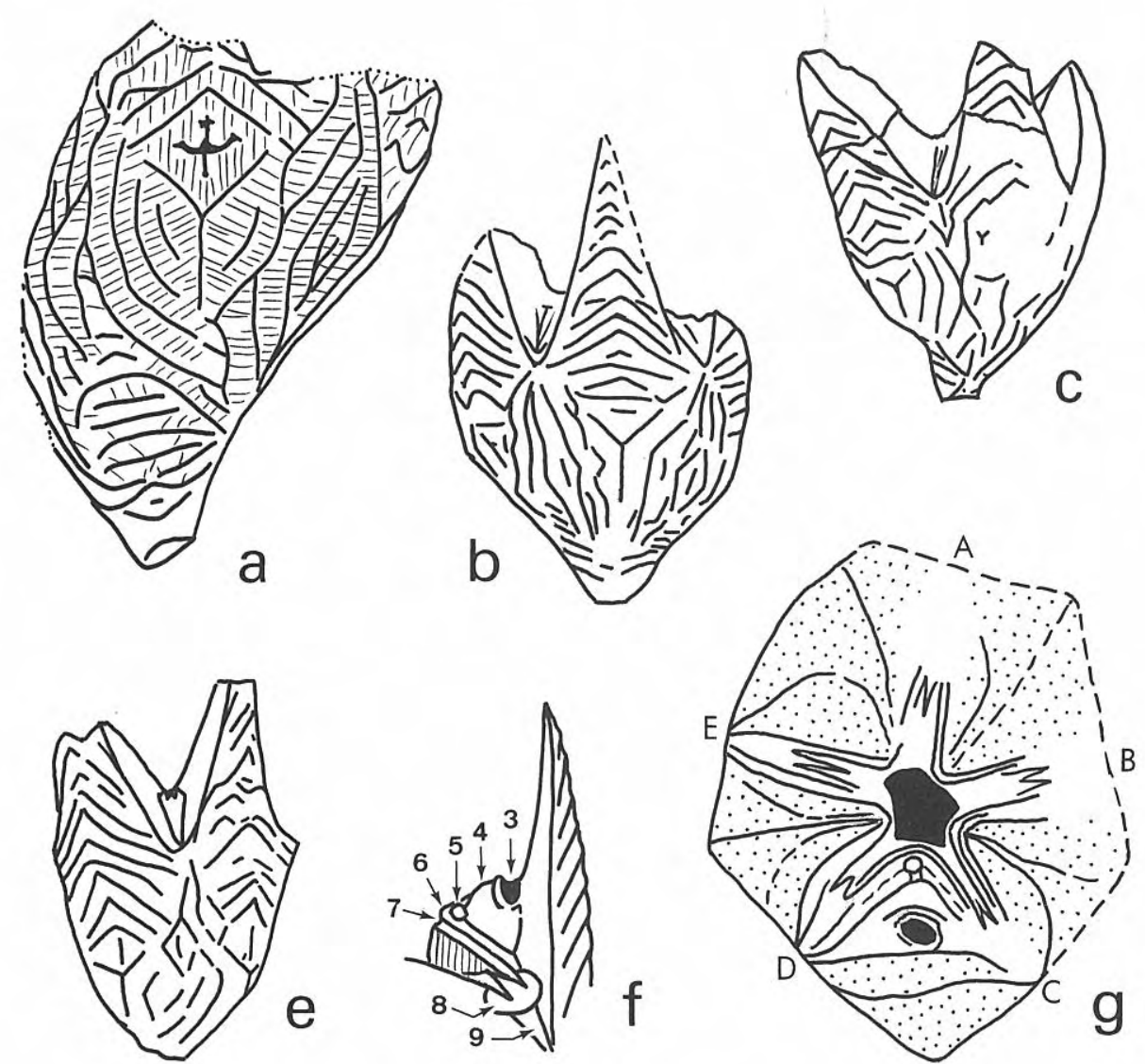
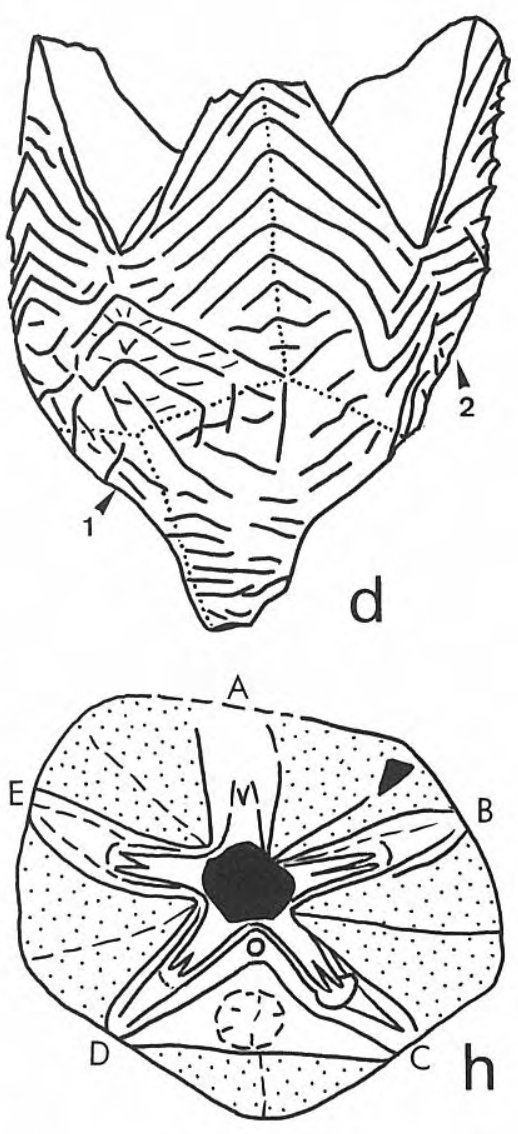

Figura 4. Mespilocystites lemenni n. sp. a-e, Esquema de la ornamentación en diferentes ejemplares, mostrando la variabilidad del recorrido de las crestas principales, más acusada en las que recubren las placas basales. a, CP-II 555 (x 10), en el que se ha representado también la estriación comarginal entre las crestas principales; b, CP-II 541 (x 5.5); c, FB-IIIB 4321 (x 5.8); d, holotipo CP-II 530 (x 5.9), en el que se indican los contornos de las placas basales (1) y radiales (2); e, CP-II 551 (x 4.9). f, Reconstrucción esquemática del proceso coronal interradial CD, mostrando en su cara adoral la apertura anal (3) sobre una subdeltoidea abultada (4), el hidroporo (5), la placa superdeltoidea estrecha (6) y la faceta de inserción de las placas ambulacrales (7). Se representa también el surco ambulacral D con sus ranuras alimenticias aparejadas, rodeadas por la faceta braquiolar (8) que da paso a la cresta articular del genículo radial (9). g-h, Detalle de la cara oral de los ejemplares CP-II 541 (g, x 8.5) y CP-II 530 (h, holotipo, x 6.7), desprovistos ambos de las placas orales y ambulacrales, dejando patente la apertura oral (en el centro). En punteado se indican los interradios con los procesos coronales.

Fay, 1962; Paul, 1985). La anchura basal de la teca de $M$. bohemicus también resulta superior, presentando una sección triangular en vez de subcircular. Los surcos radiales de esa especie poseen, tras la geniculación, un tramo más inclinado hacia fuera $\left(40^{\circ}\right)$, y la ornamentación tecal externa resulta mucho más fina, densa y regular que en la forma ibérica.

Por otra parte, M. tregarvanicus Le Menn se diferencia claramente de $M$. lemenni n. sp. por poseer una teca cónica más estrecha y elevada, de base triangular; procesos coronales prominentes, incurvados hacia el interior de la teca en sus extremos distales; y una ornamentación externa granulosa a base de estrías o crestas muy finas en disposición losángica (cf. Chauvel y Le Menn, 1973, 1979; Storch y Mergl, 1989).

A simple vista, el rasgo más distintivo de $M$. lemenni n. sp. frente a las otras dos formas del género, es su ornamentación tan acusada y característica, además de la morfología general de la teca. No obstante, ambos caracteres recuerdan superficialmente a otros coronados, como Cupulocorona rugosa Donovan y Paul o $C$. digitalis Donovan y Paul, ambas del Ashgill británico, o también, en cierto modo, a Paracystis ostrogothicus Sjöberg, del Caradoc de Suecia, que posee una ornamentación superficial grosera. Obviamente, las diferencias de $M$. lemenni n. sp. con tales especies son mucho más importantes, y se refieren a otros aspectos estructurales de la teca que fundamentan la distinción genérica.

\section{Observaciones}

La nueva especie contribuye a ampliar el conocimiento de la diversidad de un grupo, como los coronados, que incluye hasta ahora un número reducido de taxones, pese a que algunos de ellos alcanzaron una distribución muy amplia (por ejemplo el género Stephanocrinus en el Ordovícico y Silúrico de América del Norte y Europa, con una mención en el Himalaya -Gupta y Webster, 1971- 
puesta en duda por la sospechosa derivación del material de afloramientos situados en el estado de Nueva York u Ottawa: Webster, 1991).

Los representantes más antiguos de la subclase proceden del Ordovícico Superior europeo, desde donde se difunden a otros continentes a partir del Telychiense (Silúrico inferior). El origen de los coronados parece situarse en Bohemia, donde $M$. bohemicus inicia su registro en el Letnaiense (Caradoc: Aureluciense terminal). Desde allí, el grupo irradia tanto a las plataformas perigondwánicas de la "provincia de Selenopeltis" (Ibero-Armórica, Gales), como a la plataforma báltica. La principal sinapomorfía con la que comienza la diversificación de los coronados a partir de Mespilocystites es la pérdida de los surcos radiales geniculados (Donovan y Paul, 1985). La radiación consiguiente es muy rápida, pues durante el resto del Ordovícico los demás géneros de coronados ya están presentes en Gondwana (Cupulocorona), Báltica (Tormoblastus, Paracystis), o en ambos continentes (Stephanocrinus, y también Stephanoblastus si se considera el posible registro español de este último). Con respecto a los restantes coronados del Ordovícico ibérico, parece claro que $M$. lemenni puede derivar directamente de $M$. bohemicus, dadas las semejanzas morfológicas tan estrechas existentes entre ambas especies. Por su parte, $M$. lemenni precede estratigráficamente a $M$. tregarvanicus (intervalo menor de $50 \mathrm{~m}$ en la sección de Fombuena), y ambas especies podrían estar relacionadas filéticamente con $M$. bohemicus en una tendencia de inclinación progresiva de los procesos coronales hacia el interior de la teca, carácter muy común en casi todos los coronados restantes. $M$. lemenni propiamente dicho ilustra una línea de alargamiento tecal, entre las formas típicas procedentes del Miembro Piedra del Tormo de la Formación Fombuena, y el único ejemplar obtenido en el Miembro Huerva de la misma unidad en su corte tipo. Este último registro presenta además un polo aboral de sección subpentagonal y unos procesos coronales relativamente más cortos, si bien los rasgos ornamentales coinciden plenamente con los de la serie tipo de la especie.

Los vínculos evolutivos directos, postulados entre $M$. lemenni con respecto a la especie tipo del género, reflejan una vez más las afinidades biogeográficas bohémicas de parte de los equinodermos y braquiópodos articulados (Villas, 1985, 1992) de "cuño" Viniciense-Zahoraniense, identificados en la Formación Fombuena.

\section{Distribución}

Mespilocystites lemenni $\mathrm{n}$. sp. está representado en materiales del Viniciense-Zahoraniense (aprox. BurrellienseCheneyense en términos del Caradoc británico) de las Ramas Aragonesa y Castellana de la Cordillera Ibérica. En la zona Centroibérica, la especie ha sido reconocida en la parte inferior de las Pizarras Cantera, justo encima de un horizonte ferruginoso correlacionable con el nivel de hierro oolítico de la base de la Formación Fombuena, y que contiene igualmente una asociación de braquiópodos Viniciense (Villas, 1995). Los ejemplares identificados provienen de material derivado de las Pizarras Cantera en el paraje de La Palomera, aproximadamente $3 \mathrm{~km}$ al $\mathrm{O}$ de Viso del Marqués (Ciudad Real). M. lemenni n. sp. puede estar representado también en Portugal, a través de un ejemplar con procesos coronales prominentes y dirigidos hacia fuera, procedente de las pizarras micáceas con briozoos del Miembro Queixoperra de la Fomarción Cabeço do Peão (Mação).

\section{AGRADECIMIENTOS}

Los autores desean agradecer la colaboración prestada por los Dres. R. Wolf (Krefeld, Alemania), R. Prokop (Narodní Muzeum, Praga) y R. Parsley (Tulane Univ., New Orleans, USA) en distintos momentos de la redacción de este trabajo. Del mismo modo, queremos manifestar nuestra gratitud a D. Eulogio Martín por su labor fotográfica, a la Dra. I. Rábano (Museo Geominero, Madrid) por la identificación de los trilobites citados en el texto y la gestión del material estudiado, y al Dr. A. Marques Guedes (Univ. de Lisboa, Portugal) por permitirnos el acceso a los ejemplares de Mação de su colección.

Este estudio es una contribución a los Proyectos AMB92-1037-C02-01 de la CICYT, PB91-0671 de la DGICYT y al Proyecto bilateral CSIC-Academia checa de Ciencias: "Correlación bioestratigráfica entre el Ordovícico ibérico y bohémico".

\section{BIBLIOGRAFÍA}

Aznar, J.M., Olivé, A., Moissenet, E., Hernández, A. y Portero, J.M. 1983. Memoria explicativa de la Hoja $n^{o}$ 589 (Terriente) del Mapa Geológico de España a esc. 1:50.000 ( $2^{a}$ Serie). IGME, 80 págs.

Ballestra, G., Becker-Wahl, C., German, A., Höfges, J., Hoffmann, M., Kumpa, M., Marker, A., Neidhöfer, R., Rüth, H.G., Schilling, E., Wilcke, J. y Walter, R. 1982. La geología del sinclinal de Guadarranque. Münstersche Forschungen zur Geologie und Paläontologie, 56, 45-68.

Barrande, J. 1867. Système Silurien du centre de la Bohême. Ptéropodes, 3. Prague et Paris, 1-168.

Barrande, J. 1887. Système Silurien du centre de la Bohême. Cystidées. 7(1). Prague et Paris, 1-233.

Brett, C.E., Frest, T.J., Sprinkle, J. and Clement, C.R. 1983. Coronoidea: a new Class of blastozoan echinoderms based on taxonomic reevaluation of Stephanocrinus. Journal of Paleontology, 57 (4), 627-651.

Broadhead, T.W. 1982. Reappraisal of class Eocrinoidea (Echinodermata). In: Echinoderms, proceedings of the International Conference, Tampa Bay (Ed. J.M. Lawrence). Balkema, Rotterdam, 125-131.

Carls, P. 1975. The Ordovician of the Eastern Iberian Chains near Fombuena and Luesma (Prov. Zaragoza, Spain). Neues Jahrbuch für Geologie und Paläontologie Abhandlungen, 150 (2), 127-146.

Colchen, M. et Ubaghs, G.P. 1969. Sur des restes d'Echinodermes (?) du Cambro-Ordovicien de la Sierra de la Demanda (Burgos-Logroño, Espagne). Bulletin de la Societé Géologique de France (7), 11, 649-654. 
Chauvel, J. 1941. Recherches sur les Cystoïdes et les Carpoïdes Armoricains. Mémoires de la Societé Géologique et Minéralogique de Bretagne, 5, 1-288.

Chauvel, J. 1966. Echinodermes de l'Ordovicien du Maroc. Cahiers de Paléontologie, 1966, 1-120.

Chauvel, J. 1969. Données nouvelles sur le genre Destombesia Chauvel (Echinoderme Cystoïde) de l'Ordovicien de 1'Anti-Atlas marocain. Notes du Service Géologique du Maroc, 29 (213), 25-31.

Chauvel, J. 1977. Note complémentaire sur les Cystoïdes Rhombifères (Echinodermes) de l'Ordovicien marocain. Notes du Service Géologique du Maroc, 38 (268), 115139.

Chauvel, J. 1980. Données nouvelles sur quelques Cystoïdes Diploporites (Echinodermes) du Paléozoïque armoricain. Bulletin de la Societé Géologique et Minéralogique de Bretagne (C), 12 (1), 1-28.

Chauvel, J. et Le Menn, J. 1973. Echinodermes de l'Ordovicien supérieur de Coat-Carrec, Argol (Finistère). Bulletin de la Societé Géologique et Minéralogique de Bretagne (C), 4 (1), 39-61.

Chauvel, J. et Le Menn, J. 1979. Sur quelques Echinodermes (Cystoïdes et Crinoïdes) de l'Ashgill d'Aragon (Espagne). Géobios, 12 (4), 549-587.

Chauvel, J. et Meléndez, B. 1986. Note complementaire sur les Echinodermes ordoviciens de Sierra Morena. Estudios Geológicos, 42, 451-459.

Chauvel, J. et Truyols, J. 1977. Sur la présence du genre Destombesia Chauvel (Echinoderme Cystoïde) dans l'Ordovicien des Asturies (Espagne). Breviora Geologica Asturica, 21 (3), 37-40.

Chauvel, J., Meléndez, B. et Le Menn, J. 1975. Les Echinodermes (Cystoïdes et Crinoïdes) de l'Ordovicien supérieur de Luesma (Sud de l'Aragon, Espagne). Estudios Geológicos, 31, 351-364.

Delgado, J.F.N. 1908. Système Silurique de Portugal. Etude de Stratigraphie Paléontologique. Memória da Comissão do Serviço Geológico de Portugal, 1-245.

Dereims, A. 1898. Recherches géologiques dans le Sud de l'Aragon. Thèse Doctorale. Annales Hebert, Lille, 2, 1199.

Donovan, S.K. and Paul, C.R.C. 1985. Coronate echinoderms from the Lower Palaeozoic of Britain. Palaeontology, 28 (3), 527-543.

Fay, R.O. 1962. Mespilocystites, an Ordovician coronate crinoid from Czechoslovakia. Oklahoma geology Notes, 22, 156-161.

Fortey, R.A., Harper, D.A.T., Ingham, J.K., Owen, A.W. and Rushton, A.W.A. 1995. A revision of Ordovician series and stages from the historical type area. Geological Magazine, 132 (1), 15-30.

Gil Serrano, G. 1985. Memoria explicativa de la Hoja $n^{o}$ 707 (Logrosán) del Mapa Geológico de España, esc. 1:50.000 (2 ${ }^{a}$ Serie). IGME, 31 págs.

Gupta, V.J. and Webster, G.D. 1971. Stephanocrinus angulatus Conrad (Crinoidea) from the Silurian of Kashmir. Palaeontology, 14 (2), 262-265.

Gutiérrez-Marco, J.C. 1980. Graptolitos del Ordovícico del Sistema Ibérico. Tesis de Licenciatura, Universidad Complutense, 1-186, Madrid (inéd.)
Gutiérrez-Marco, J.C. 1981. Informe paleontológico y bioestratigráfico sobre el Ordovícico y Silúrico de la Rama Castellana del Sistema Ibérico. Informe Interno MAGNA 1:50.000, Hojas N ${ }^{O S}$ 565, 566 y 589, 16 págs., IGME, Madrid.

Gutiérrez-Marco, J.C. 1986. Graptolitos del Ordovícico español. Tesis Doctoral, Universidad Complutense, 3 vols., 701 págs, Madrid (inéd.)

Gutiérrez-Marco, J.C. y Rábano, I. 1987. Trilobites y graptolitos de las lumaquelas terminales de los "Bancos Mixtos" (Ordovícico superior de la Zona Centroibérica meridional): elementos nuevos o poco conocidos. Boletín Geológico y Minero, 98 (5), 647-669.

Gutiérrez-Marco, J.C., Chauvel, J., Meléndez, B. y Smith, A.B. 1984a. Los equinodermos (Cystoidea, Homalozoa, Stelleroidea, Crinoidea) del Paleozoico inferior de los Montes de Toledo y Sierra Morena (España). Estudios Geológicos, 40, 421-453.

Gutiérrez-Marco, J.C., Robardet, M. y Rábano, I. 1984b. Estudio bioestratigráfico del Ordovícico en el sinclinal del Valle (provincia de Sevilla, SO de España). Memórias e Noticias, Coimbra, 97, 12-37.

Gutiérrez-Marco, J.C., Meléndez, B. y Chauvel, J. 1991. Equinodermos (Cistideos y Blastozoos) del Llandeilo y Caradoc (Ordovícico) de la Cordillera Ibérica. Resúmenes de las Comunicaciones presentadas a las VII Jornadas de Paleontología, Oviedo, 37.

Gutiérrez-Marco, J.C., Meléndez, B., Parsley, R.L., Prokop, R.J. y Marek, L. 1992. Equinodermos (Cystoidea, Homalozoa, Asterozoa) de afinidades bohémicas en el Ordovícico de las Zonas Centroibérica y Ossa Morena, España. Publicaciones del Museo de Geología de Extremadura, 1, 79-81.

Gutiérrez-Marco, J.C., Rábano, I., San José, M.A., Herranz, P. and Sarmiento, G.N. 1995. Oretanian and Dobrotivian stages vs. "Llanvirn-Llandeilo" Series in the Ordovician of the Iberian Peninsula. In: Ordovician Odyssey: Short papers from the Seventh International Symposium on the Ordovician System (Eds. J.D. Cooper, M.L. Drosser and S.C. Finney), The Pacific Section Society for Sedimentary Geology, California, 55-59.

Hafenrichter, M. 1979. Paläontologisch-ökologische und lithofazielle Untersuchungen des "Ashgill-Kalkes" (Jungordovizium) in Spanien. Arbeiten aus dem Paläontologisches Institut Würzburg, 3, 1-139.

Hammann, W. 1992. The Ordovician trilobites from the Iberian Chains in the province of Aragón, NE-Spain. I. The trilobites of the Cystoid Limestone (Ashgill Series). Beringeria, 6, 3-219.

Hammann, W., Robardet, M. and Romano M. 1982. The Ordovician System in southwestern Europe (France, Spain and Portugal). Correlation Chart and Explanatory Notes. International Union of Geological Sciences, Publication 11, 1-47.

Havlícek, V. and Marek, L. 1973. Bohemian Ordovician and its international correlation. Casopis pro mineralogii a geologii, 18, 225-232.

Havlícek, V. and Vanèk, J. 1966. The Biostratigraphy of the Ordovician of Bohemia. Sborník Geologických Vèd, Paleontologie, 8, 7-69. 
Josopait, V. 1972. Das Kambrium und das Tremadoc von Ateca (Westliche Iberische Ketten, NE-Spanien). Münstersche Forschungen zur Geologie und Paläontologie, 23, 1-121.

Kesling, R.V. 1962. An interpretation of Rhombifera bohemica Barrande 1867, an unusual hydrophoridean cystoid. Contributions Museum of Paleontology, University of Michigan, 17 (13), 277-289.

Kesling, R.V. 1968. Cystoids. In: Treatise on Invertebrate Paleontology, Pt. S, Echinodermata 1. (Ed. R.C. Moore). The Geological Society of America \& University of Kansas Press, Lawrence, S85-S267.

Kolb, S. 1978. Erläuterungen zur Geologische Kartierung des Gebietes S. Cerveruela in den Östlichen Iberischen Ketten (NE-Spanien). Diplomarbeit Universität Würzburg, 1-112 (inéd.).

Lotze, F. 1929. Stratigraphie und Tektonik des Keltiberischen Grundgebirges (Spanien). Abh. Ges. Wiss. Göttingen math.-phys. kl. N.F., 14 (2): (Beiträge Geol. Westl. Mediterr.), 1-120. Traducción española: Estratigrafía y tectónica de las cadenas paleozoicas Celtibéricas. Publicaciones Extranjeras sobre Geología de España, 8, 1-313, Madrid 1955.

Meléndez, B. 1944. Contribución al estudio del Paleozoico aragonés. Trabajos del Instituto de Ciencias Naturales “José de Acosta”, Serie Geológica, 3 (1), 1-149.

Meléndez, B. 1959. Los Echinosphaerites del Silúrico de Luesma (Zaragoza). Estudios Geológicos, 15, 269-276.

Meléndez, B. et Chauvel, J. 1982. Sur quelques Cystoidées cités par les Drs. J. Almera et M. Faura dans 1'Ordovicien de Barcelone. Acta Geológica Hispánica, 14 (1979), 318-321.

Meléndez, B. y Hevia, I. 1947. La fauna ashgilliense del Silúrico aragonés. Boletín de la Universidad de Granada, 19, 247-259.

Parsley, R.L. 1990. Aristocystites, a recumbent diploporid (Echinodermata) from the Middle and Late Ordovician of Bohemia, CSSR. Journal of Paleontology, 64 (2), 278-293.

Paul, C.R.C. 1977. Evolution of primitive echinoderms. In: Patterns of Evolution. (Ed. A. Hallam). Elsevier, Amsterdam, 123-158.

Paul, C.R.C. 1985. Ordovician and Silurian coronates (Echinodermata) from Czechoslovakia. Geological Journal, 20, 21-29.

Paul, C.R.C. 1988. The phylogeny of the cystoids. In: Echinoderm phylogeny and evolutionary biology. (Eds. C.R.C. Paul and A.B. Smith). Clarendon Press, Oxford, 199-213.

Renard, H. 1967. Sur la présence du genre Rhombifera dans les calcaires à Cystoïdes de l'Ashgill de la MontagneNoire et d'une nouvelle espèce: Rhombifera matteii. Comptes Rendus sommaires des Séances de la Société Géologique de France, 1967 (7), 298-299.

Riba Arderiu, O. 1959. Estudio geológico de la Sierra de Albarracín. Monografías del Instituto "Lucas Mallada”, C.S.I.C., 16, 1-283.

Sacher, L. 1963. Stratigraphische Untersuchungen und Kartierung im Gebiet zwischen der Sierra de Aragoncillo und dem Rio Tajo (Prov. Guadalajara,
Spanien). Diplomarbeit Universität Heidelberg, 1-106 (inéd.).

Scheuplein, R. 1970. Stratigraphie und Tektonik der Schichtenfolge im Raume Daroca/Calamocha (Westliche Iberische Ketten, NE Spanien). Dissertation Universität Würzburg, 1-106 (inéd.).

Sprinkle, J. 1973. Morphology and evolution of blastozoan echinoderms. Harvard University Museum of Comparative Zoology, Special Publication, 1-283.

Sprinkle, J. 1980. Origin of blastoids: new look at an old problem. Geological Society of America Abstracts with Programs, 12 (7), 528.

Sprinkle, J. 1995. Do eocrinoids belong to the Cambrian or to the Paleozoic Evolutionary Fauna?. In: Ordovician Odyssey: Short papers from the Seventh International Symposium on the Ordovician System (Eds. J.D. Cooper, M.L. Drosser and S.C. Finney), The Pacific Section Society for Sedimentary Geology, California, 397-400.

Storch, P. and Mergl, M. 1989. Králodvor/Kosov boundary and the late Ordovician environmental changes in the Prague Basin (Barrandian area, Bohemia). Sborník Geologických Vëd, Geologie, 44, 117-153.

Villas, E. 1983. Las formaciones del Ordovícico medio y superior de las Cadenas Ibéricas y su fauna de braquiópodos. Estudios Geológicos, 39, 359-377.

Villas, E. 1985. Braquiópodos del Ordovícico medio y superior de las Cadenas Ibéricas Orientales. Memorias del Museo Paleontológico de la Universidad de Zaragoza, 1 (1-2), 1-153.

Villas, E. 1992. New Caradoc brachiopods from the Iberian Chains (Northeastern Spain) and their stratigraphic significance. Journal of Paleontology, 66 (5), 772-793.

Villas, E. 1995. Caradoc through Early Ashgill Brachiopods from the Central-Iberian zone (Central Spain). Geobios, 28 (1), 49-84.

Villas, E., Harper, D.A.T., Mélou, M. and Vizcaïno, D. 1995. Stratigraphical significance of the Svobodaina species (Brachiopoda, Heterorthidae) range in the Upper Ordovician of South-Western Europe. In: Ordovician Odyssey: Short papers from the Seventh International Symposium on the Ordovician System (Eds. J.D. Cooper, M.L. Drosser and S.C. Finney), The Pacific Section Society for Sedimentary Geology, California, 97-98.

Webster, G.D. 1991. An evaluation of the V.J. Gupta echinoderm papers, 1971-1989. Journal of Paleontology, 65 (6), 1006-1008.

Wolf, R. 1976. Erläuterungen zur geologischen Kartierung des Gebietes zwischen Santed, Used and Orcajo in den Westlichen Iberischen Ketten (NE-Spanien). Diplomarbeit Universität Würzburg, 1-118 (inéd.).

Wolf, R. 1980. The lower and upper boundary of the Ordovician System of some selected regions (Celtiberia, Eastern Sierra Morena) in Spain. Part I: The Lower Ordovician sequence of Celtiberia. Neues Jahrbuch für Geologie und Paläontologie Abhandlungen, 160 (1), 118-137.

Manuscrito recibido: 25 de julio, 1995 Manuscrito aceptado: 20 de octubre, 1995 